NASA Technical Memorandum 81427

\title{
CALCULATED AND EXPERIMENTAL DATA \\ FOR A 118-mm BORE ROLLER BEARING \\ TO 3 MILLION DN
}

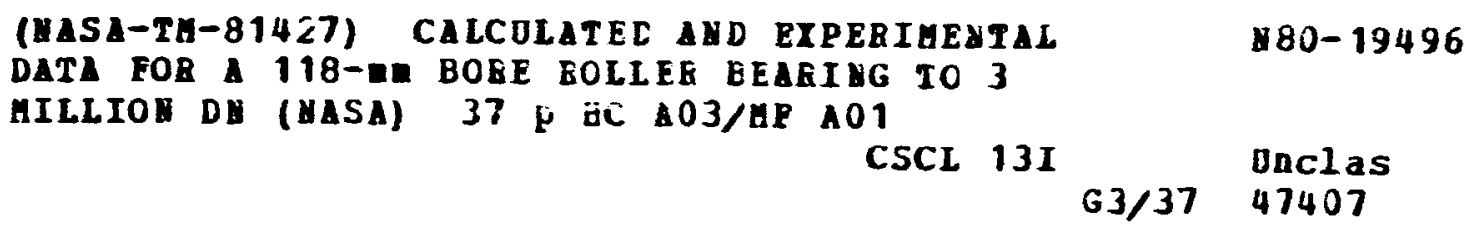

Harold H. Coe and Fredrick T. Schuller

Lewis Research Center

Cleveland, Ohio

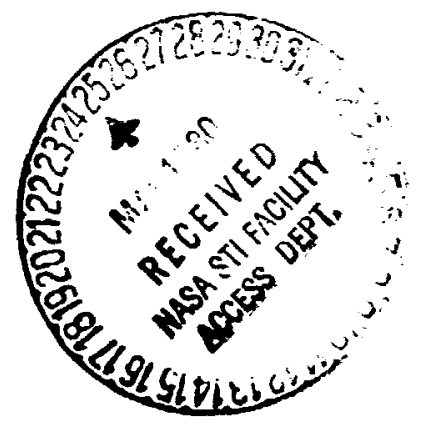

Prepared for the

International Lubrication Conference

cosponsored by the American Society of Mechanical Engineers

and the American Society of Lubr ication Engineers

San Francisco, California, August 18-21, 1980 


\title{
Caldulated and EXPERIMENIAL data FUK A 118-mo \\ GORE KOLLER BEARING TO 3 MLLLION UN \\ by Harold $H$. Coe and Fredrick 1 . Schuller \\ National Aeronautics and Space Administration \\ Lewis Research Center \\ Cleveland, Ohio
}

\begin{abstract}
Operating characteristics for a $118-\mathrm{mm}$ bore cylind 1 cal roller bearing were calculated using the computer program CYBEAN. The predicted results of innerand outer-race temperatures and heat transferred to the lubricant generally compared well with experimental data for shaft speeds to 3 million DN (25 $500 \mathrm{rpm})$, radial loads to $8900 \mathrm{~N}(2000 \mathrm{lb})$ and total lubricant flow rates to $0.0102 \mathrm{~m}^{3} / \mathrm{min}(2.7 \mathrm{gal} / \mathrm{min})$.
\end{abstract}

\section{INTRODUCT ION}

For the last several years, trends in gas turbine design have indicated that future aircraft. engines may require bearings that can operate reliably at DN values of 3 million or higher $[1-3]$ (the speed parameter DN is the bearing bore in millimeters multiplied by the shaft speed in rpm). Consequently, there has been a large amount of work done in the area of highspeed bearings in recent years. Successful operation of ball bearings at 3 million DN was reported $[4,5]$. Roiler bearings were operated to 3 million DN $[3,6]$.

The question of how to design bearings for high-speed applications is increasingly being answered by computer studies $\mid 3,7\}$. There are currently several comprehensive computer programs in use that are capable of predicting rolling bearing operating and performance chi racteristics (e.g. , (8-13]). These programs generally accept input data of bearing internal geometry (such as sizes, clearance, and contact angles), bearing material 
and lubricant properties, and bearing operating conditions (load, speed, and anbient temperature). The prograns then sol ve several sets of equations that characterize rolling-element bearings. The output produced typically consists of rolling-element loads and Hertz stresses, operating contact angles, conponent speeds, heat generation, local temperatures, bearing fatigue life, and power 10ss. In $[14]$, data were published which compared computer predictions with actual ball bearing performance. However, little data has been published which compare computer predictions with actual cylindrical roller bearing performance.

As reported in $(8-10]$, a computer program called CYBEAN has recently been developed for analysis of high-speed cylindrical roller bearings. It is therefore the objective of the work reported here in to compare the values of inner- and outer-race temperatures, cage speed, and heat transferred to the lubricant calculated using the computer program CYBEAN, with the corresponding experimental data for the 118-millimeter bore bearing described in $[6]$.

\section{BEARING TEST DATA}

The experimental data used for comparison purposes in this report were initially reported in [6]. In this reference, a large bore roller bearing was tested at speeds up to 3 million DN, loads up to $8900 \mathrm{~N}(2000 \mathrm{lb})$ and with total oil flow rates up to 0.0102 cubic meters per minute ( $2.7 \mathrm{gal} / \mathrm{min})$. Lubrication was provided to the test bearing through axial grooves under the inner race with small radial holes through to the rolling elements. The inner ring was also cooled by oil flowing through axial grooves that did not have any radial holes. About one-half of the total oil int roduced to the inner ring was used for cooling only. 
The lubricant used was a tetraester, type 11 oil qualified to the MIL-L-23699 specification. The major properties of the oil are listed in Table 1. The bearing tester is described in detail in $[6]$.

The test bearing was a roller bearing with a 118-millimeter bore, a flanged inner ring, and 28 rollers, each 12.65 millim ters (0.4979 in.) diameter by 14.56 millimeters (0.573 in.) long. More complete specifications a re shown in Table 2.

$0 \mathrm{il}$ inlet temperature was held constant at $366 \mathrm{~K}\left(200^{\circ} \mathrm{F}\right)$. Accurate measurement of bearing oil inlet and outlet temperatures allowed determination of the amount of heat transferred to the lubricant at any operating condition. Data were recorded at bearing loads of $2220,4450,6010$, and $8900 \mathrm{~N}(500,1000,1500$, and $20001 \mathrm{~b})$, and at shaft speeds of 10000 , 15000,20000 , and $25500 \mathrm{rpm}$. The total oil flow rates to the inner ring varied from 0.0019 to 0.0102 cubic meter per minute $(0.5$ to $2.7 \mathrm{gal} / \mathrm{min})$ THE COMPUTER PROGRAM

The comprehensive computer program CYBEAN, for analysis of a single cylindrical roller bearing, is completely described in [8-10]. This program is capable of calculating the thermal and kinematic performance of high-speed bearings and includes a roller skew prediction for misaligned conditions. The calculations include determination of inner and outer-ring cemperatures, oil outlet temperatures, cage speed, and bearing power loss.

Use of CYBEAN to predict bearing performance requires as input an estimate of the volume percent of the bearing cavity that is occupied by the lubricant. The bearing cavity is defined as the space between the innerand outer-races that is not occupied by the cage or the rolling elements. The authors of [9] recommended that the values used be less than 5 percent. 
When CYBEAN is also used for thermal analysis, additional input is required, since all the themal nodes nust be defined. The maximum number of nodes permitted is 100 . For this investigation, 41 nodes were used, including 19 in the lubricant system, as shown in Fig. 1(a). Later four metal nodes were added (causing the two known-temperature nodes to be renumbered) as shown in Fig. $1(b)$.

RESULTS AND DISCUSSION

To effect the direct comparison of predicted and experimental bearing performance, the computer program was generally run at the stated operating conditions of the bearing tested [6]. All combinations of load, speed and flow rate were not computed, because they a re not all necessary for comparison purposes and would require unnecessary computer time. Therefore, the effect of load was calculated using one speed (20000 rpm), the effect of speed was determined using one 1 oad $(8900 \mathrm{~N}(2000 \mathrm{lb}))$ and the effect of flow rate was observed using one load and two speeds $(8900 \mathrm{~N}(2000 \mathrm{lb}))$ and ( 20000 and $25500 \mathrm{rpm}$ ).

Effect of Lubricant Volume

To determine how the race temperatures and bearing heat generation vary with the value assumed for percent lubricant in the bearing cavicy, the program was run for several values of this volume percent at the $4450 \mathrm{~N}$ (1000 1b), 20000 rpm condition. The total oil flow rate chosen was $0.0057-$ cubic meter per minute $(1.5 \mathrm{gal} / \mathrm{min})$. The results are shown in Fig. 2 . Note that in all the figures in this report, the calculated values are always just connected with straight line segments. Also shown are the corresponding experimental data points. 
The race temperatures (Fig. $2(a)$ ) increased with increasing lubricant volume. This would be expected since the fluid dray on the rollers and the cage would increase with the amount of liquid available. Over the full range of 5 percent oil volume, the temperature changes seem to be linear and not too large, about 5 percent at these conditions.

The total heat generated in the bearing (Fig. 2(b)) increased with increasing lubricant volume. These changes were also linear but the total change in heat generation over the volume range was a more significant 50 percent. Since Ref. 6 includes data on heat transferred to the lubricant (as an indication of the power loss within a bearing), this type of data was calculated from the computer predicted oil-outlet temperature and is also shown in Fig. 2(b). The amount of heat transferred to the oil closely follows the amount of heat generated in the bearing. Over this range of volume percent, the amount of heat transferred to the lubricant is about 90 percent cf the heat generated in the bearing. Based on the experimental data for this test condition, the range of volume percent from 1 to 5 percent is adequate for the outer-race temperature and the heat transferred to the oil. The calculated inner-race temperature remained below the experimental value for the whole volume range.

Effect of Bearing Load and Speed

The computer program was run to determine the effect of bearing load on race temperature and heat generation. Calculations were made with a lubricant flow rate of 0.0057 cubic meter per minute $(1.5 \mathrm{gal} / \mathrm{min})$ for two lubricant volumes ( 2 and $3 \%$ ), and a shaft speed of $20000 \mathrm{rpm}$. The results, compared with experimental data, a re shown in Fig. 3 fur radial luads from 2220 to $8900 \mathrm{~N}(500$ to 2000 1b). The predicted race temperatures (Fig. 
$3(a)$ ) increase very slightly over the load range and the experimental values are practically constant. While the outer-race temperatures compare favorably, the predicted inner-race temperatures remain about 10 percent lower than the test values. The amount of heat transferred to the oil, predicted using the lubricant volume of 2 percent, compares very well with the test data (fig. 3(b)).

The effect of shaft speed was observed by using the program with an 8900 N (2000 1b) load for several values of shaft speed. The flow rate was set at 0.0057 cubic meters per minute $(1.5 \mathrm{gal} / \mathrm{min})$ and the lubricant volume at 2 percent. The results are shown in Fig. 4 for shaft speeds from 10000 to $25500 \mathrm{rpm}$ ( 1.2 to $3.0 \mathrm{milli}$ ( DN). The predicted values of outer race temperature (Fig. $4(\mathrm{a})$ ) compared to the experimental data, are slightly high at the lower speeds and slighty low at the higher speeds. The predicted inner-race temperature, fairly close to the experimental data at the lower speeds, becomes very low at the higher speeds. The heat transferred to the oil, however, as predicted by the program compared very well with the experimental values over the whsle speed range (Fig. $4(\mathrm{~b})$ ). It is therefore apparent that the calculations for the total bearing heat generation seem to be correct, but that insufficient heat transfer is predicted to the inner race at the higher speeds. At this point it is not clear whether the discrepancy with the inner-race temperature is a problem of using a proper thermal model, or of using proper input data.

Ef fect of Lubricant Flow Rate

Since the oil flow rate can have a significant effect on bearing temperature and power loss, the computer program was run over a range of oil flow rates from 0.0038 to 0.0102 cubic meter per minute $(1.0$ to $2.1 \mathrm{gal} / \mathrm{min})$ 
for several values of lubricant volume percent. Calculations were made at $8900 \mathrm{~N}(2000$ lb) load for both 20000 and $25500 \mathrm{rpm}$. The results are shown in Figs. 5 and 6 . The calculated trends are in the right direction, that is, the race cemperatures are reduced by increasing the oil flow rate, for the values of lubricant volume shown. The calculated outer-race temperatures for $20000 \mathrm{rpm}$ ( $\mathrm{Fig}$. 5(a)) are reasonable for volumes of 2 or 4 per cent, while the calculated inner-race temperatures remain low over the entire flow rate range. The computed heat transferred to the oil (Eig. $5(b))$ at $20000 \mathrm{rpm}$ compares fairly well with the test data over the flow range for these two set values of lubricant volume. The comparisons at 25500 rpm (Fig. 6) are very similar to those of $20000 \mathrm{rpm}$ (Fig. 5). From these figures, it is not clear how the lubricant volume should vary with flow rate. The outer-race temperature comparison would indicate that the volume percent should decrease with flow rate. A comparison of the heat transferred to the lubricant suggests that the lubricant volume should increase with flow

rate. More work needs to be done in this area. Effects of Miscellaneous Input Data Several calculations were made in an effort to detect any errors in data input or thermal modelling. The program was run at the $8900 \mathrm{~N}$ (2000 lb), $25500 \mathrm{rpm}$ condition with a flow rate of 0.0102 cubic meters per minute $(2.7 \mathrm{gal} / \mathrm{min})$. The convergence criterion (used with an iterative procedure to determine when a solution has been reached-explained in detail in (9)) was changed from 0.1 to 0.05 and 0.01 and the calculated temperatures remained the same. A bearing misalignment of 5 minutes was assumed, and the race temperatures changed only 1 Kelvin. An additional 300 watts heat seneration was arbitrarily added to nodes 1 and 3 (shaft 
ends, see Fig.l(a)) (In case the support bearing heat generation was not properly accounted for). While this managed to raise the inner-race cemperatures 3 Kelvin, the cemperature of nodes 1 and 3 became unacceptably high, $610 \mathrm{~K}\left(638^{\circ} \mathrm{F}\right)$. The nodal structure was changed slightly by adding four nodes, two on the shaft and two on the inner ring adapter (as shown in Fig. $1(b))$. The resulting calculated temperatures did not change. The value of the heat transfer coefficient relating the rotating shaft and inner ring adapter to the air in the rig cavity (e.g., from node 41 to node 21 , Fig. $1(b))$ was changed from 981 to 170 watts per square meter-degree $C$. The inner-race temperature change 1 Kelvin. It was concluded that, since none of the above items had any significant effect on the bearing race temperatures, the inner-race temperatures were mostly affected by the bearing's internally generated heat.

\section{Effect of Diametral Clearance}

One item that could have a large effect on the bearing heat generation is the diametral clearance, that is, the total free movement of the bearing components in a radial direction. Initial calculations using the original thermal nodes (Fig. I(a)) showed only a small change in inner race temperature from a clearance of 0.12 millimeter (maximum unmounted value) down to 0.001 millimeter. However, [6] suggests that a negative clearance exists at $25500 \mathrm{rpm}$, so additional calculations were made, using the nodal structure of Fig. 1(b), for several values of negative clearance. The results are shown in Fig. 7. The increase in inner-race temperature as the clearance is lowered below zero is dramatic, and approaches the experimental value closely when the clearance is a minus 0.02 millimeter. At this point, and for the first time, all 28 rollers are loaded at the inner ring. At minus 0.01 
millimeter clearance, 13 of the rollers were loaded at the iuner race. These calculations indicate that it is very likely the bearing (6) was indeed operating with a negative clearance at $25500 \mathrm{rpm}$.

For comparison purposes, the data of Fig. 6 were recalculated using a diametral clearance of minus 0.02 millimeter. These results are shown in Fig. 8. Both race temperatures (Fig. $8(a)$ ) and heat transferred to the lubricant (Fig. $8(b))$, compare very well with the experimental data.

Although the computer program CXBEAN has the capability of evaluating bearings with out-of-round outer raceways, the program at'this point did not predict the effective bearing operating clearance (i.e., the diametral clearance that would exist at operating speed and temperature). Since it became very evident that this was an important parameter for high speed bearings, subroutines were added to CYBEAN to calculate shanges in diametral clearance due to initial fits and due to temperature and high-speed effects. Further calculations were then made utilizing this capability. The program CYBEAN was run for several values of bearing unmounted diametral clearance $t_{u}$ detemine the values of diametral clearance of the mounted bearir.g at operating speeds and temperatures calculated by the program. This clearance, which does not yet contain the effects of bearing load, will be called the effective hot mounted diametral clearance. The bearing conditions used were: $8900 \mathrm{~N}(2000$ 1b) 10ad, 25500 rpm shaft speed, 0.0102 cubic meter per minute $(2.7 \mathrm{gal} / \mathrm{min})$ lubricant flow rate, and a lubricant volume of 2 percent. The initial shaft-inner ring interference was set at $0.0712 \mathrm{millimeter}$ on the diameter. The results are shown in Fig. 9. With the actual measured value of $0.12 \mathrm{millimeter}$ for cold, unmounted diametral clearance, the program predicted about $0.03 \mathrm{millimeter}$ 
remaining as the effective hot mounted clearance at operating conditions. To obtain a negative effective clearance, closer to the value of minus 0.02 millimeter noted previously, an input of only 0.09 millimeter initial unmounted clearance had to be used. Again, at this point, all 28 rollers are in contact with the inner race. It is interesting to note the large change in fatigue life of this bearing as the clearance gets smaller and the number of rollers in contact with the inner race gets larger. At first, the fatigue life increases, and probably becomes a maximum at just that point where all 28 rollers are first in contact. The fatigue 1 ife then decreases rapidly as the tighter clearance causes increased stress.

To check program predictions at other conditions, CYBEAN was operated with an input of $0.09 \mathrm{millimeter} \mathrm{cold,} \mathrm{unmounted} \mathrm{diametral} \mathrm{clearance} \mathrm{for}$ several values of lubricant flow rate. The first calculations were for the $8900 \mathrm{~N}(2000$ 1b) $25500 \mathrm{rpm}$ condition, while the second calculations were for the 8900 N (2000 lb), $20000 \mathrm{rpm}$ condition. The lubricant volume was 2 percent. The results are shown in Figs. 10 and 11 . In Fig. 10, the program predicted race temperature for $25500 \mathrm{rpm}$ shaft speed that had the corrfet trend with lubricant flow rate and were exceptionally close to the experimental values. The heat transferred to the oil (Fig. 1U(b)) also compared well with the experimental data, although the value at the low flow rate is almost two $\mathrm{kW}$ low. In Fig. 11, however, while the predicted trends were correct for $20000 \mathrm{rpm}$, the calculated inner-race temperatures were almost 30 Kelvin low. The outer-race temperatures compared fairly well. The heat transferred to the oil (Fig. $11(\mathrm{~b}$ ) ) was also reasonably close, although at the highest flow rates the calculated values we re about $2 \mathrm{~kW}$ low. 
Two final checks were made with CYBEAN, using the original cold unmounted diametral clearance of 0.12 millimeter. The first check was with several loads at the low speed (10000 cpm) condition. This low speed condition was chosen because of the large values of cage slip indicated (6). All previous calculated values of cage slip were less than 1 percent at $8900 \mathrm{~N}(2000 \mathrm{lb})$ and up to 3 percent at $2220 \mathrm{~N}(500 \mathrm{lb})$. The experimental values at the higher speeds (20000 and $25500 \mathrm{rpm})$ were all less than 2 percent. The flow rate was set at 0.0102 cubic meter per minute (2.7 $\mathrm{gal} / \mathrm{min})$ and the lubricant volume at 2 percent. The results are shown in Fig. 12. Here, the inner-race temperature predictions are close to the experimental values, and the outer-race temperature predictions are about 20 Relvins higher than the corresponding data. The calculated heat transferred to the oil compares well (Fig. 12(b)), and were slightly higher than the test values. However, while the tests indicated cage slips of over 46 percent, for the entire load range from 2220 to $8900 \mathrm{~N}(500$ to $2000 \mathrm{lb})$, the corresponding predicted values were all less than 3 percent. Without this slip, the experimental temperatures would have been somewhat higher, judging from [6], where the bearing temperatures varied inversely with cage slip. The calculated effective hot mounted diametral clearance was about 0.08 millimeter.

The second check was to run the program at the high speed condition (25 $500 \mathrm{rpm})$ with $8900 \mathrm{~N}(2000 \mathrm{lb})$ load, set the misalinement angle to 5 minutes, and see if the resulting skew would be sufficient to change the predicted race temperatures significantly. This calculation showed the inner-race temperature to be only $8 \mathrm{Kel}$ vin higher with skewing and the outer-race temperature was 3 Kelvin higher. The heat iransferred to the 
lubricant was the same. The calculated effective hot mounted clearance was about 0.03 millimeter. Since the 5 minute misalignment angle is lerge for this test rig, it may be concluded that the presence of misalinement alone would not have been sufficient to cause the experimental inner-race temperatures to be so much higher than calculated values. Since the effect of misalinement on bearing temperatures was small, and the amount of computer time increased by a factor of 10 , no further calculations were made with misalinement.

\section{Roller Loads, Film Thickness and Skew Angle}

While the main focus of the work reported herein was to calculate bearing characteristics that were measured experimentally, the program CYBEAN does provide calculated values of other items of interest. Some of these are: The EHD film thickness at the roller-raceway contact, the individual roller-race contact loads and stresses, the roller-cage forces, and, with misalinement, the roller-flange forces and the roller ikew and tilt angles. Several of these items are shown in Figs. 13 to $1 \%$. The calculations were performed for a shaft speed of $25500 \mathrm{rpm}$, a radial load of $8900 \mathrm{~N}$ $(2000 \mathrm{lb})$, a flow rate of $0.0102 \mathrm{~m}^{3} / \mathrm{min}$, and a lube volume of 2 persent. The values of the EHD film thickness for the most heavily loaded roller contact, calculated for those conditions of Fig. 9 are shown in Fig. 13. The film thickness is plotted as a function of the calculated effective hot mounted clearance. Also shown is the corresponding roller contact load. In general, the film thickness diminishes and the contact loads increase rapidly once the bearing clearance becomes negative and all the rollers are in contact with the inner ring (see Fig. 9). Other calculations with a fixed diametral clearance as input for those same bearing operating conditions 
(see Fig. 7) indicate that the film thickness changes very little as the clearance increases from zero to $0.12 \mathrm{~m}$. The corresponding outer-ring contact load continues to increase slightly and reaches $4000 \mathrm{~N}$ at $0.12 \mathrm{~mm}$ clearance. Likewise, the inner ring load increases to $2600 \mathrm{~N}$ at $0.12 \mathrm{am}$ clearance.

The inner and outer-ring contact loads for each ruller, calculated for these same conditions cre shown in fig. 14 for two values of hot mounted clearance. For the 0.031 clearance bearing, there are 7 rollers in contact with the inner ring and the reaining rollers have only the centrifugal loading at the outer ring. When all 28 rollers are in contact at the clearance of $-0.028 \mathrm{~mm}$, the maximur load is about the same. However, all the other rollers are carrying heavier loads at both the inner and outer rings than with the positive c'earance. When the clearance was at a $-0.039 \mathrm{~mm}$, the contact loads for each of the 28 roilers increased by $1000 \mathrm{~N}$ at both the inner and outer rings. The calculaticn for inese same operating conditions with a 5 minute misalinement, where the hot mounted clearance was $0.029 \mathrm{~mm}$, showed little change from the contact loads of the $0.031 \mathrm{~mm}$ clearance curve. The program estimates of the rollercage forces are shown in $\mathrm{Fig} .15$ for three combinations of hot mounted clearance and misalinement angle. A positive force means the cage is pushing the roller. With no misalinement the maximum cage forces we re about $10 \mathrm{~N}$. For the same clearance, with a 5 minute misalinement, the cage Forces seemed to be all very small. With a large clearance of $0.12 \mathrm{~mm}$, however, and a 5 minute misalinement, the maximum cage force reached $25 \mathrm{~N}$. These forces are of the same order of magnitude as those measured experimentally for the same size bearing $[15,16]$ (The sign convention in $(15,16]$ is of the opposite sense to that used here). 
The flange axial forces calculated for the same two cases with the 5 minute misalinement are shown in Fig. 16. These forces are small, about the same order of magnitude as the cage-roller forces. The iarger clearance bearing shows less roller-flange contact.

The predicted roller skew angle for these same two cases is shown in Fig. 17. In both cases, there is a negative skew angle at the load $20 n e$. For the $0.029 \mathrm{~mm}$ clearance case, the remainder of the rollers exhibit a positive skew angle of about the same size. With the large $0.12 \mathrm{~mm}$ clearance, however, the remaining roliers show essentially zero skew. The skew angle shown is the angle of the roller relative to the inner ring, and is called the relative skew angle. The angle of the roller relative to the outer ring, called the absolute skew angle, would be the relative angle plus (or minus) the amcunt of the misalinement present at that particular roller position.

\section{CONCLUDI NG REMARKS}

In general, the CYBEAN computer program as utilized predicted values of outer-race temperature and heat transferred to the oil that compared reasonably well with the corresponding experimental data. However, the calculated values of inner-race cemperature were usually somewhat low, especially at the higher shaft speeds. The program did not predict the high cage slip experienced [6] at the lower shaft speeds. This is probably the reason the experimental temperatures were lower than the calculated values for those conditions. Nevertheless, it should be noted that on the basis of absolute temperatures all calculated values were within 10-percent of the corresponding experimental daca and most were within 5 percent. Considering th: nature of heat transfer calculations, this is reasonably close correlation. 
The calculations performed show the importance of the effective hot mounted diametral clearance for useful bearing operation. Care hould be taken that the bearing effective diametral clearance remins positive at all operating conditions to assure obtaining a reasonable rolling-element fatigue life for the bearing.

As for the bali bearing computer program SHABERTH $[12\}$, the largest unknown quantity of the input data required for CYBEAN is the volume percent of lubricant in the bearing cavity. The values chosen for these calculations were in the range recomended [9]. From the comparisons riesented in this paper, it can be conluded that the values of percent lubricant used are reasonably correct for this program. However, just how these values should vary with oil flow rate andfor shaft speed is still not clear.

SUMMARY OF RESULTS

The computer program CYBEAN was used to predict inner and outer-race temperatures, cage speed, and heat transferred to the lubricant for a 118-millimeter bore cylindrical rolle; bearing. The results, calculated over a range of operating conditions, were compared with experimental data obtained previously. The bearings were operated at radial loads of 2220 , 4450,6670 , and $8900 N(500,1000,1500$, and $20001 \mathrm{~b})$ and at shaft speeds of $10000,15000,20000$, and $25500 \mathrm{rpm}$. The bearings were lubricated and cooled by flowing oil through and under the inner race at total rates of 0.0038 to 0.0102 cubic meter per minute $(1.0$ to $2.7 \mathrm{gal} / \mathrm{min})$. The oil inlet temperature was maintained constant at $366 \mathrm{~K}\left(200^{\circ} \mathrm{F}\right)$. The following results we re obtained:

1. The cylindrical roller bearing analysis computer program (CYBEAN) can predict outer-race temperature and the amount of heat transferred to the lubricant reasonably well. 
2. At the higher shaft speeds, the calculated inner-race temperatures were unch lower than the corresponding experimental data, unless the effective hot diametral clearances were set negative about 0.02 millimeter.

3. A bearing can operate with an effective hot mounted diametral clear ance of zero or less, but the calculated fatigue life decreases rapidly once all of the rollers are in contact with the inner race.

4. The computer program did not predict the high cage slip experimentally obtained with the roller bearing at low shaft speeds.

5. The computer escimated values of roller-cage forces were of the same order of magnitude as that obtained experimentally for the same size bearing. REFERENCES

1. Brown, P. F., "Bearings and Dampers for Advanced Jet Engines," SAE Paper No. 700318 , Apr. 1970.

2. Yovinelli, Jr., V. P., "Current Seal Designs and Future Requirements for Turbine Engine Seals and Bearings," Journal of Aircraft, Vol. 12, No. 4, Apr. 1975, pp. 266-273.

3. Brown, P. F., et al., "Mainshaft High Speed Cyliudrical Koller Bearings for Gas Turbine Eng ines," FR-8015, Pratt \& Whitney Aircraft Croup, West Palm Beach, FL, Anr. 1977.

4. Holmes, P. W., "Evaluation of Drilled-Ball bearings at DN Values to Three Million. I - Variable Oil fiow Tests," NASA CR-2004, 1972.

5. Signer, H., Bamberger, E. H., and Zaretsky, E. V., "Parausetric Study of the Lubrication of Thrust Loaded $120-\mathrm{mm}$ bure Ball Bearings to 3 Million DN," Journal of Lubrication Technology, Vol. 90, No. 3, July 1974, pp. $515-524$.

6. Schuller, F. T., "Operating Characteristics ol a Large bore Roller bearing to speeds of $3 \times 10^{\circ}$ DN," NASA rp-1413, ly\%y. 
7. Kennedy, F. E. and lheng, H. S., eds., Computer-Aided Design of Bearings and Seals, American Society of Mechanical Engineers, 1976.

8. Kleckner, R. J. and Pirvics, J., "High Speed Cylindrical Roller Bearing Analysis. SKF Computer Program CYBEAN. Volume I: Analysis," AL78P022-VOL-1, SKF Industries, Inc., King of Prussia, PA, July 1978. ( MASA CR-159460)

9. Kleckner, R. J. and Pirvics, J., "High Speed Cylinder Roller Bearing Analysis. SKF Computer Program CYBEAN. Volume II: User's Manual," AL78P023-WL-2, SKF Industries, Inc., King of Prussia, PA, July 1978. (NASA CR-159461)

10. Kleckner, R. J., Pirvics, J., and Castelli, V., "High Speed Cylindrical Rolling Element Bearing Analysis "CYBEAN" Analytical Formulation," ASME Paper No. 79-LUB-35, Oct. 1979.

11. Crecelius, W. J. and Pirvics, J., "Computer Program Operation Manual on SHABERTH: A Computer Program for the Analys is of the Steady State and Transient Thermal Performance of Shaft-Bearing Systems," SKF-AL76P030, SKF Industries, Inc., King of Prussia, PA, July 1976.

12. Crecelius, W. J., Heller, S., and Chiu, Y. P., "Improved Flexible ShaftBearing Thermal Analysis with NASA Friction Models and lage tifects," SKF-AL76P003, SKF Industries, Inc., King of Prussia, PA, Feb. 1976.

13. Gupta, P. K., "Dynamics of Rolling Element Bearings, Part I, Part II, Part I I , Part IV," Journal of Lubrication Technology, Vol. 101, No. 3, July 1979, pp. 293-326.

14. Coe, H. H. and Zaretsky, E. V., "Predicted and Experimental Performance of Jet-Lubricated 120-Millimeter-Bore Ball Bearings Operating to 2.5 Million DN," NASA TP-1196, 1978. 
15. Nypan, L. J., "Roller to Separator Contact Forces and Cage to Shaft Speed Ratios in Rollet Bearings," MASA CR-3048, 1978.

16. Nypan, L. J., "Separator Contact Forces and Speed Ratios in Roller bearings," ASLE Preprint No. 79-LC-4D-1, Oct. 1979.

TABLE 1. - PROPERT IES OF TETRAESTER LUBRICANT [5]

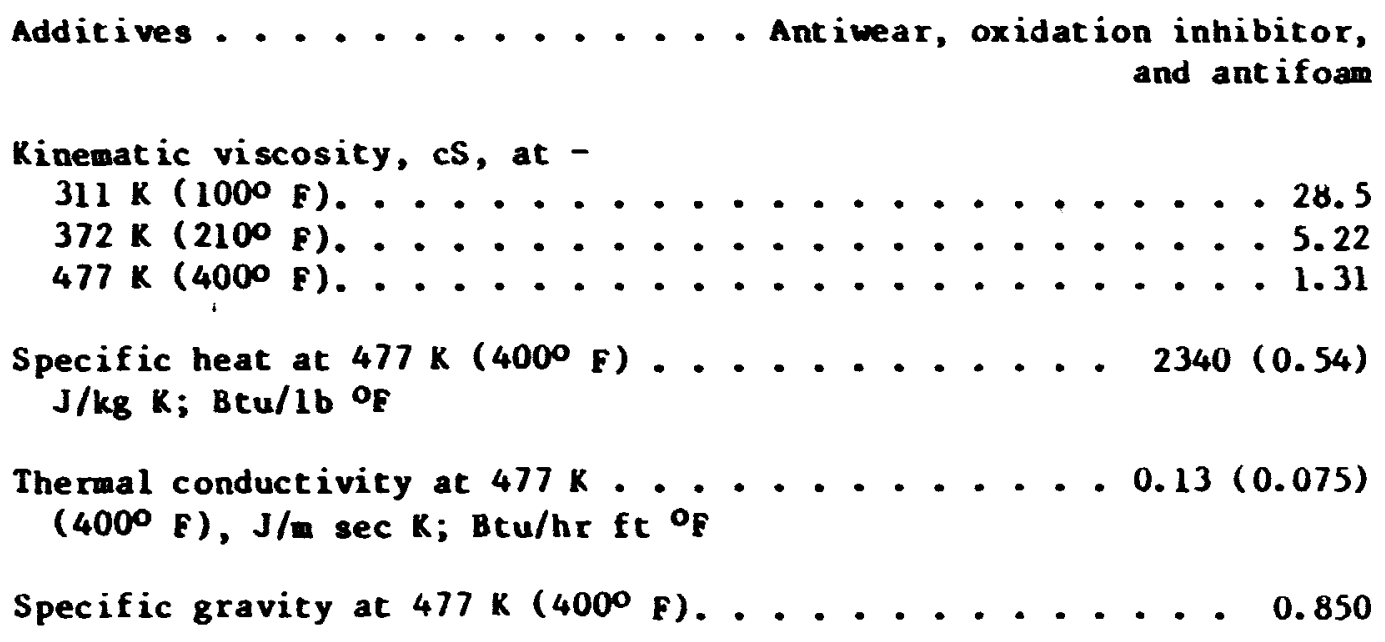


TABLE 2. - ROLLER-BEARING SPECIFICATIONS

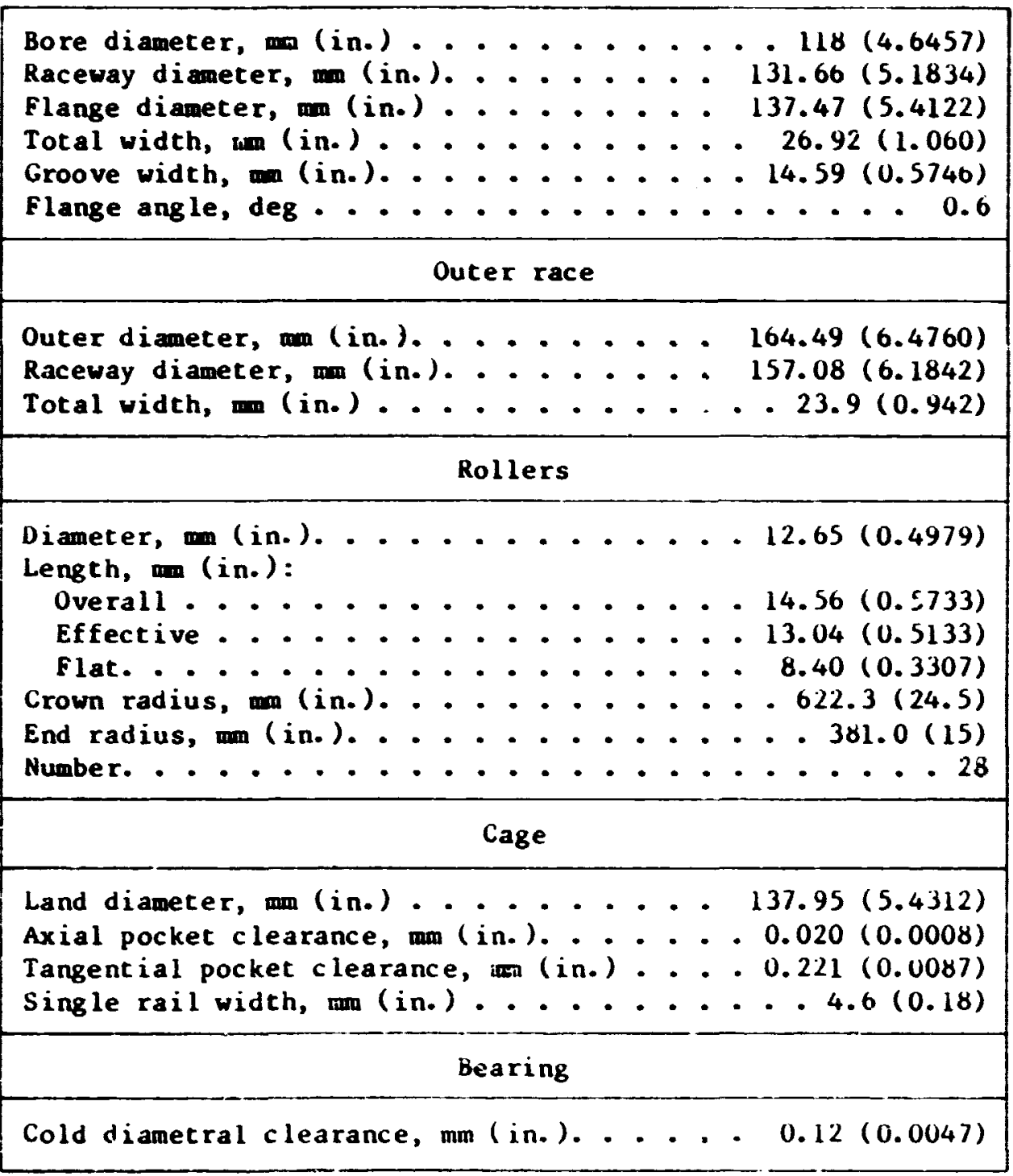


TABLE 1. - PROPERTIES OF TETRAESTER LUBRICANT ${ }^{2}$

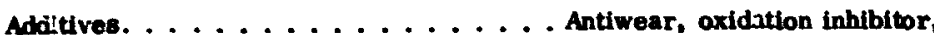
and antifoam

Kinematic viscosity, cS, at -

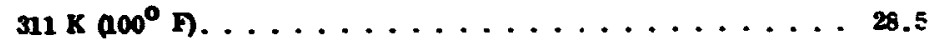

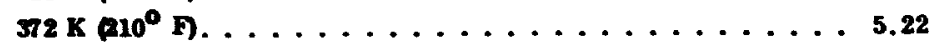

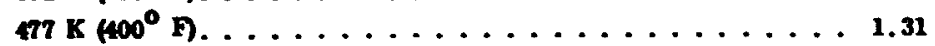

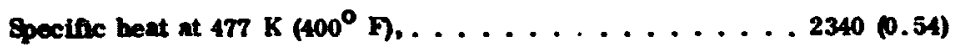

$\mathrm{J} / \mathrm{kg} \mathrm{K} ; \mathrm{Bu} / \mathrm{hb}^{\circ} \mathrm{F}$

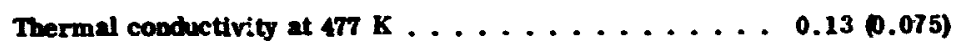
$\left(400^{\circ} \mathrm{F}\right) \mathrm{J} / \mathrm{m} \sec \mathrm{K} ; \mathrm{Btu} / \mathrm{hr} \mathrm{ft}^{\circ} \mathrm{F}$

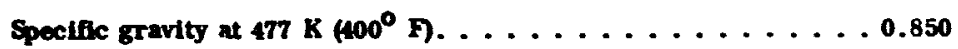

From reference 5 .

TABLE II. - ROLLER-BE ARING SPECIFICATTONS

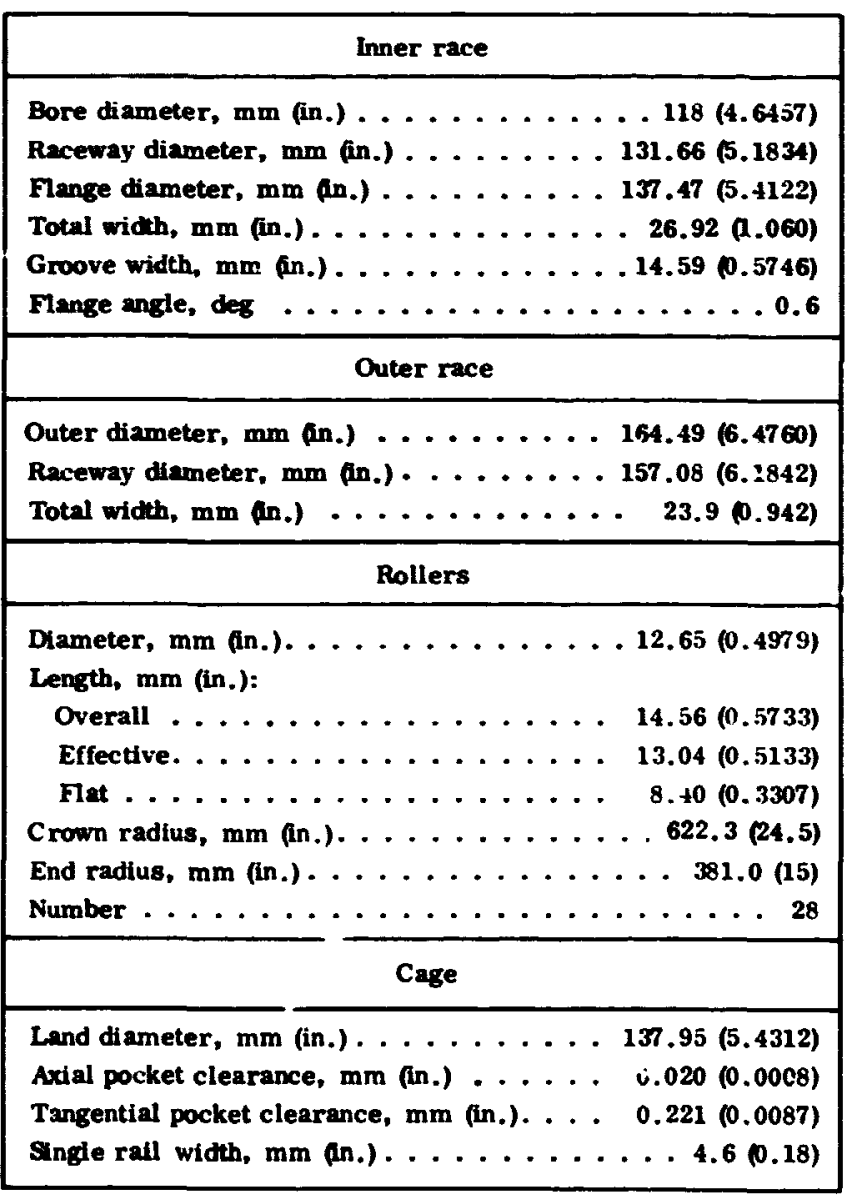



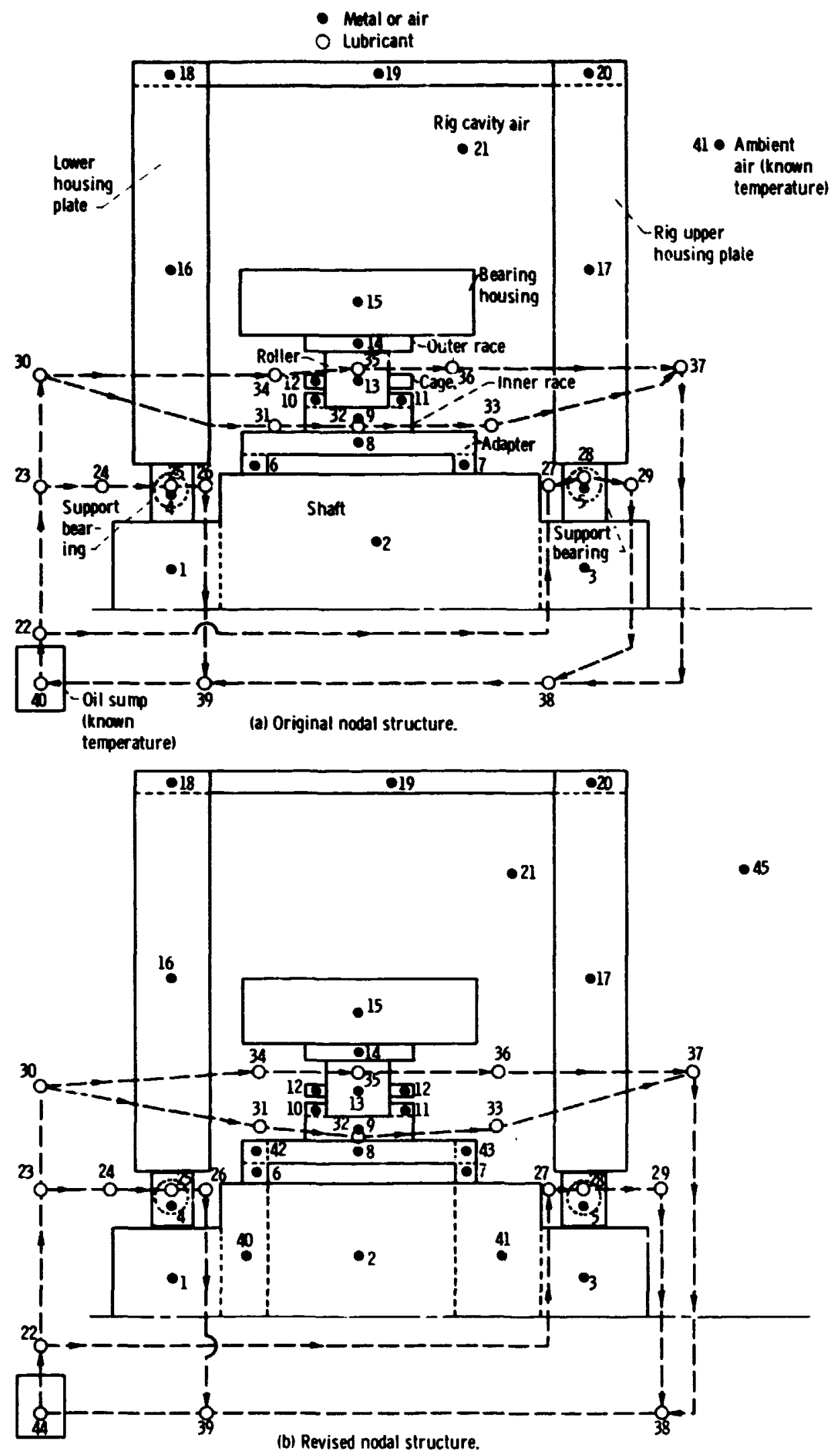

Figure 1. - Nodal system used for ther mal routines in CYBEAN. 

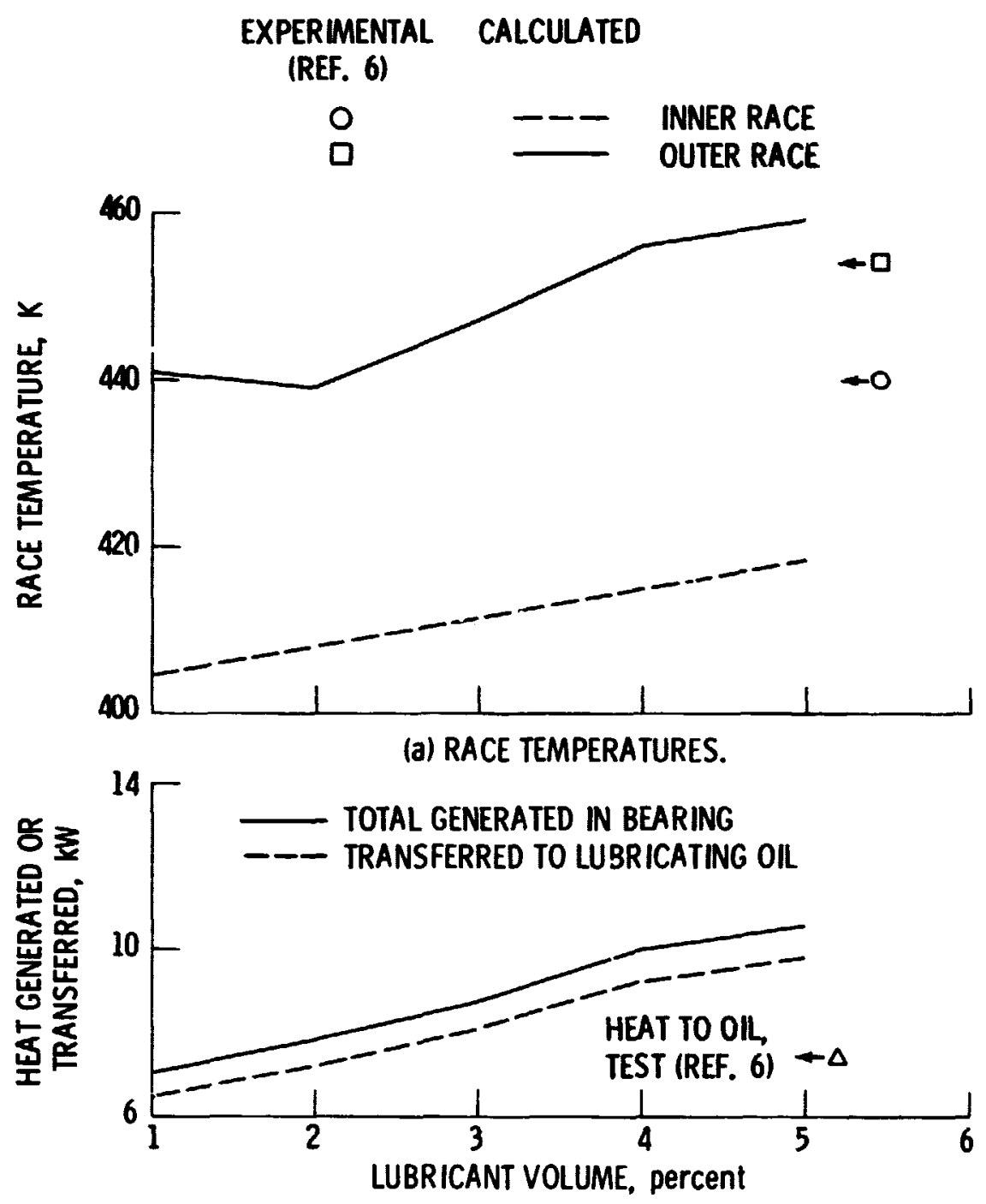

(b) HEAT GENERATED IN BEARING, OR TRANSFERRED TO LUBRICANT.

Figure 2. - Calculated values of bearing operating characteristics as functions of lubricant volume fraction. Test data shown for comparison. Load, $4450 \mathrm{~N}(1000 \mathrm{lb})$; shaft speed, $20000 \mathrm{rpm}$; lubricant flow rate, 0.0057 cubic meter per minute $(1.5 \mathrm{gal} / \mathrm{min})$. 


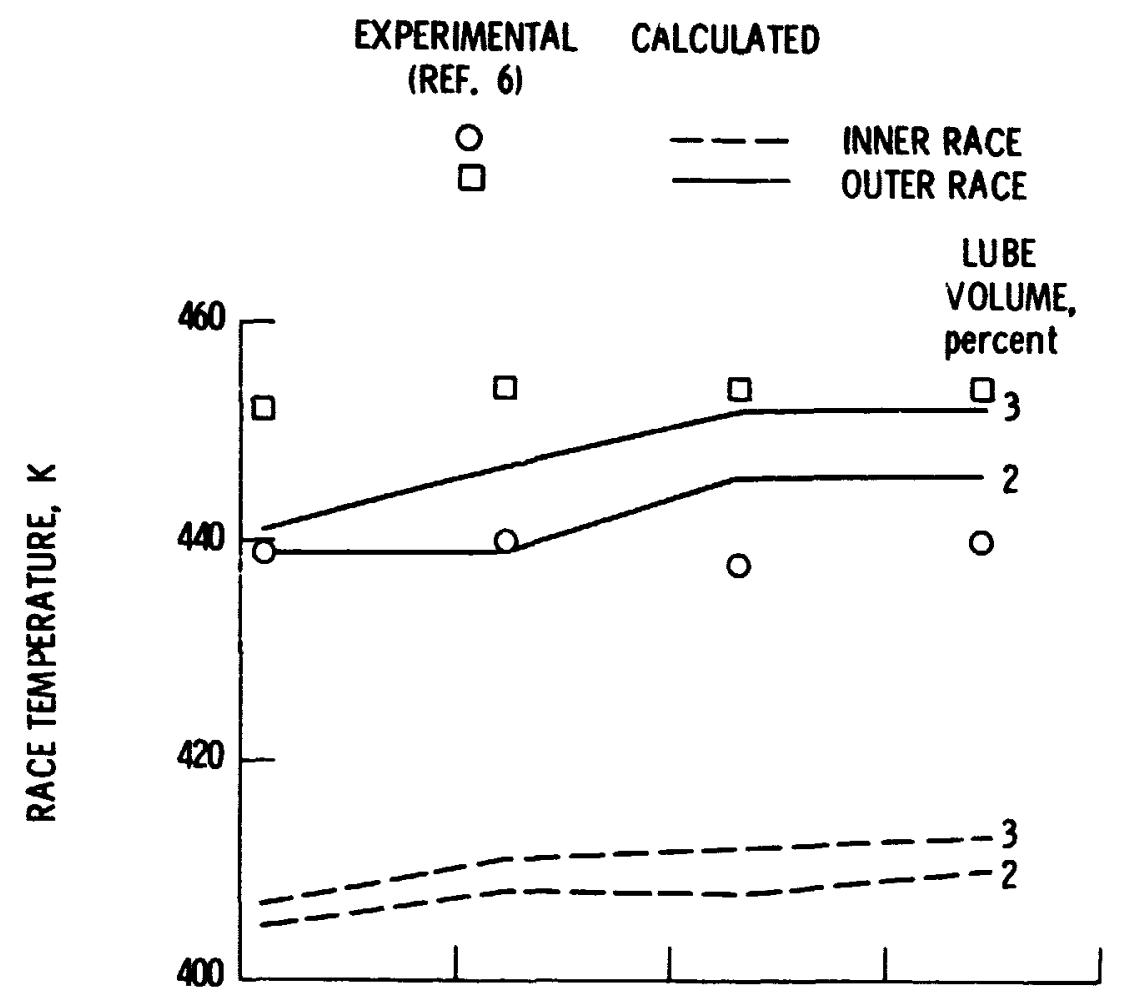

(a) RACE TEMPERATURES.

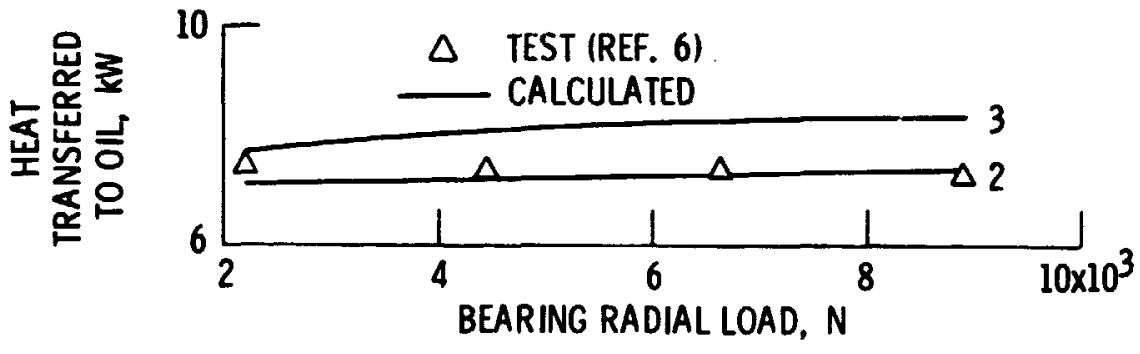

(b) HEAT TRANSFERRED TO LUBRICATING OIL

Figure 3. - Comparison of calculated and experimental values of bearing cperating characteristics as functions of radial load. Shaft speed, $20000 \mathrm{rpm}$; lubricant flow rate, 0.0057 cubic meter per minute $(1.5 \mathrm{gal} / \mathrm{min})$. 


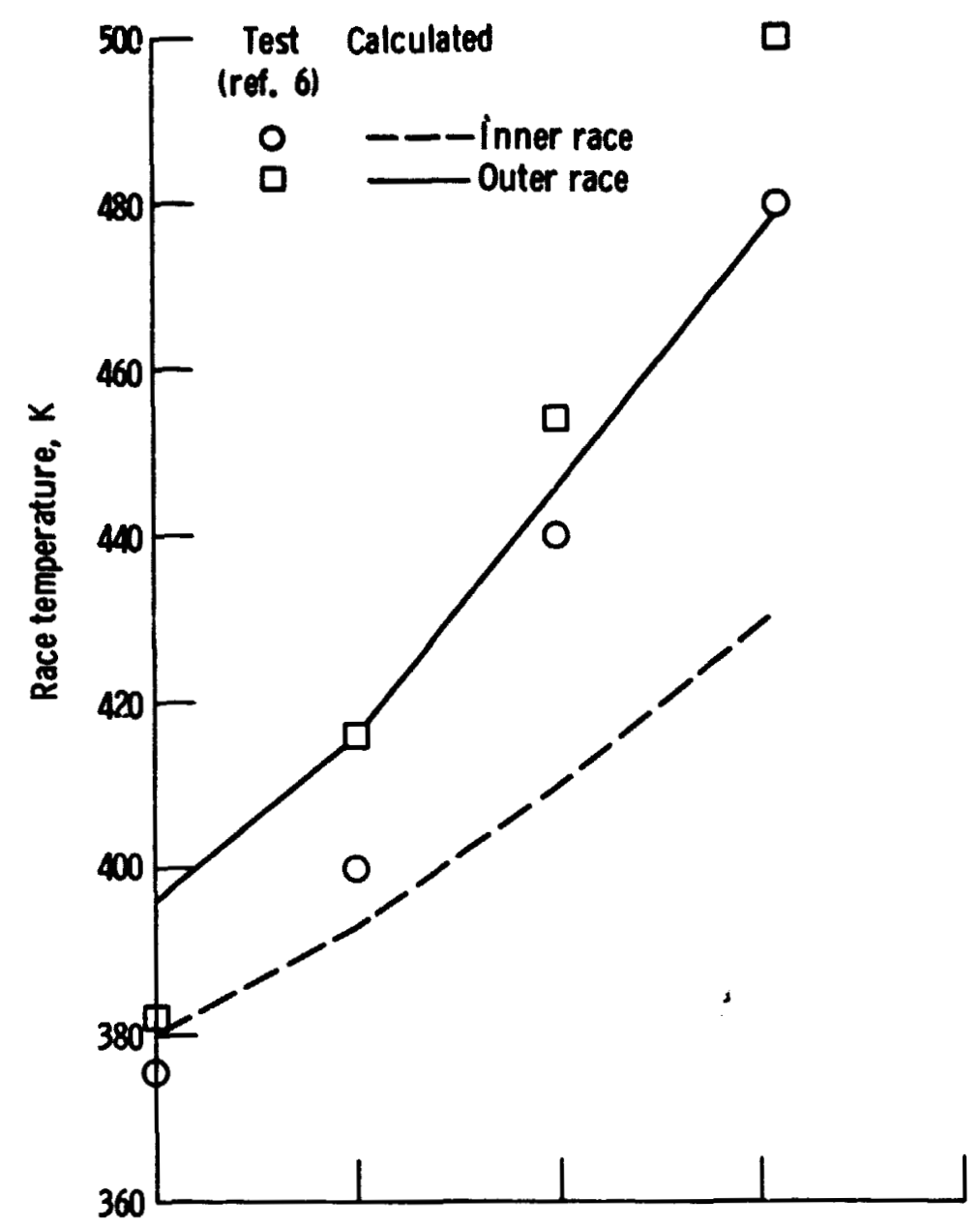

(a) Race temperatures.

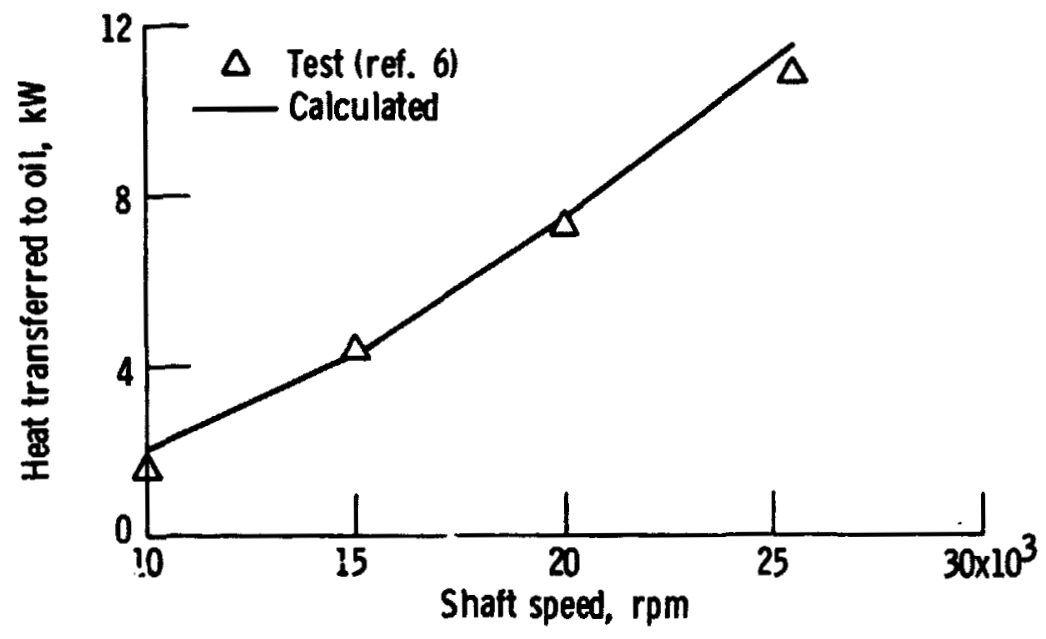

(b) Heat transferred to lubricating oil.

Figure 4. - Calculated and experimental values of bearing operating characteristics as a function of shaft speed. Load, $8900 \mathrm{~N}(2000 \mathrm{lb})$; lubricant flow rate, 0.0057 cubic meter per minute $(1.5 \mathrm{gal} / \mathrm{min})$; lubricant volume, 2 percent. 


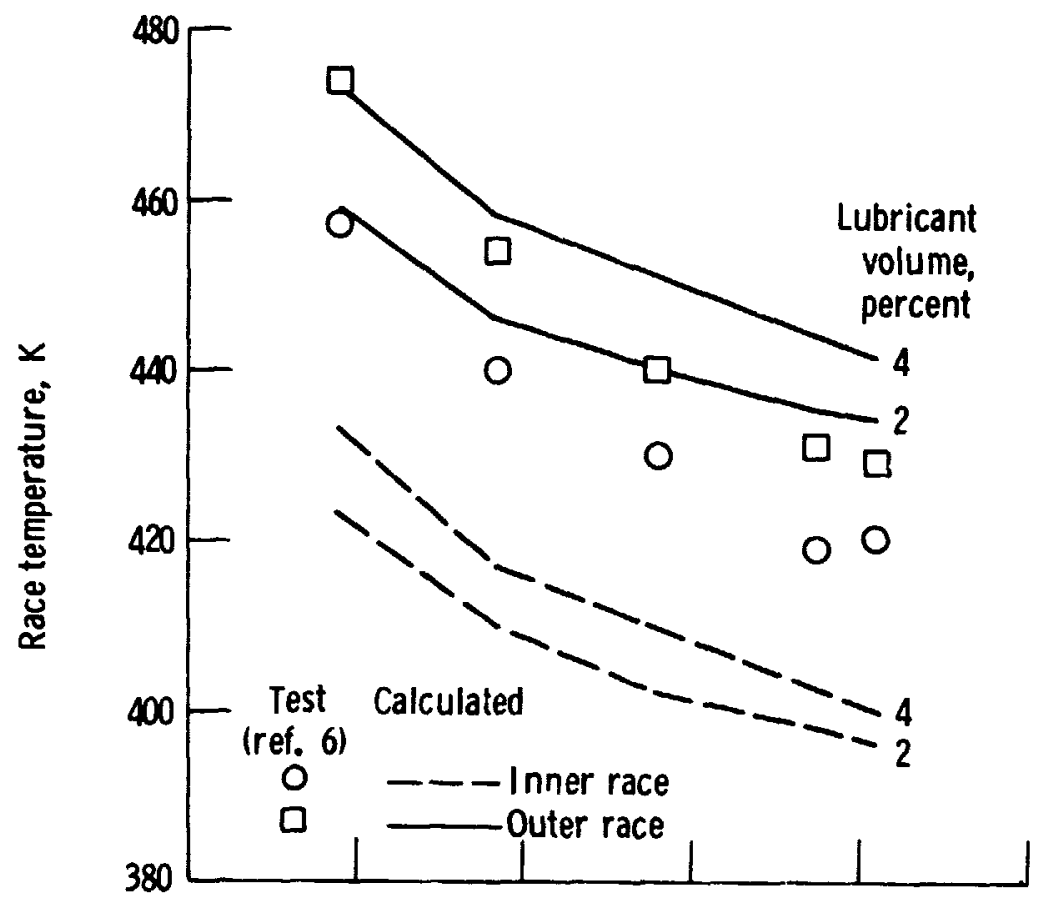

(a) Race temperatures.

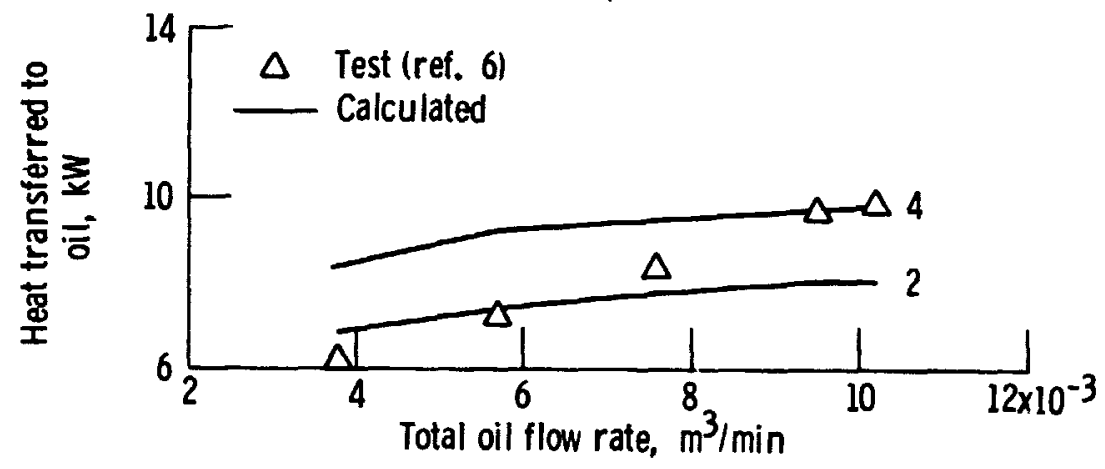

(b) Heat transferred to lubricating oil.

Figure 5. - Calculated and experimental values of bearing operating characteristics as functions of total oil flow rate. Shaft speed, $20000 \mathrm{rpm}$; radial load, $8900 \mathrm{~N}$ (2000 lb). 
Test Calculated

(ref. 6)

O - - Inner race

- $\longrightarrow$ Outer race

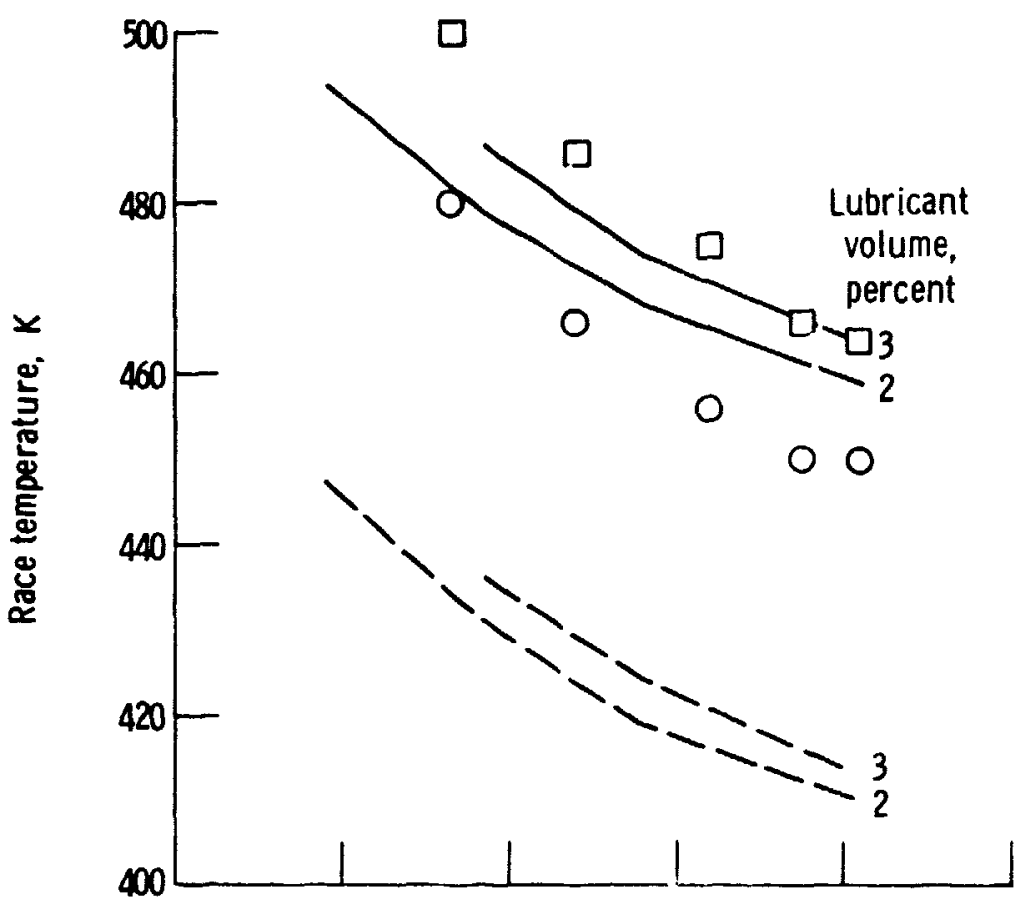

(a) Race temperatures.

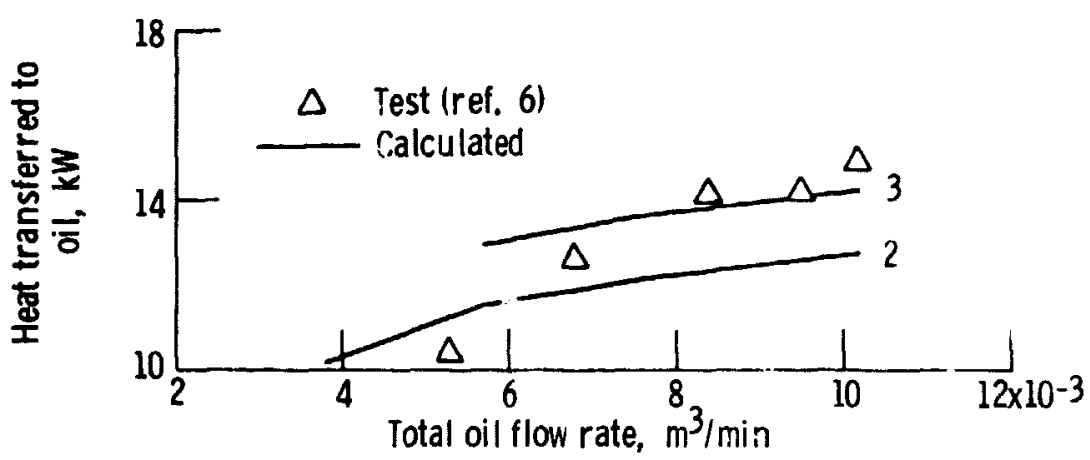

(b) Heat transferred to lubricating oil.

Figure 6. - Calculated and experimental values of bearing operating characteristics as functions of total oil flow rate. Shaft speed, $25500 \mathrm{rpm}$; radial load, $8300 \mathrm{~N}$ (2000 lb). 
TEST CALCULATED

(REF. 6)

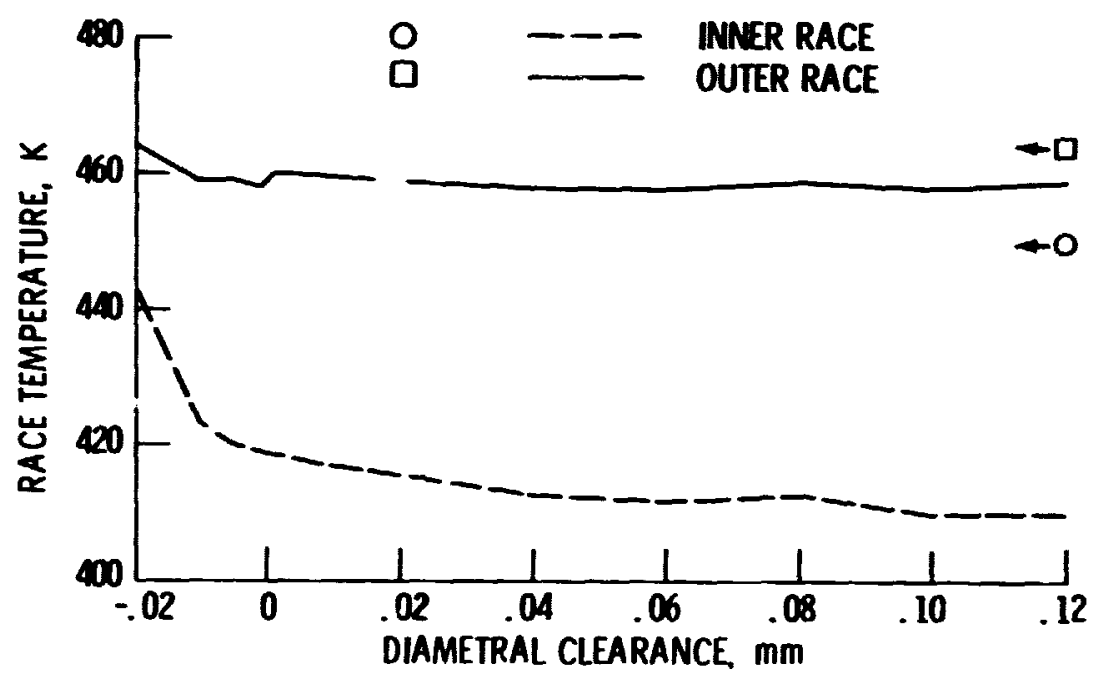

Figure 7. - Calculated race temperatures as a function of diametral clearance. Shaft speed, $25500 \mathrm{rpm}$; radial load, $8900 \mathrm{~N}$ (2000 lb); total oil flow rate, 0 0102 cubic meter per minute (2.7 gal/min); lubricant voluu.e, 2 percent. Test values shown for comparison, plotted at maximum possiole ciearance. 

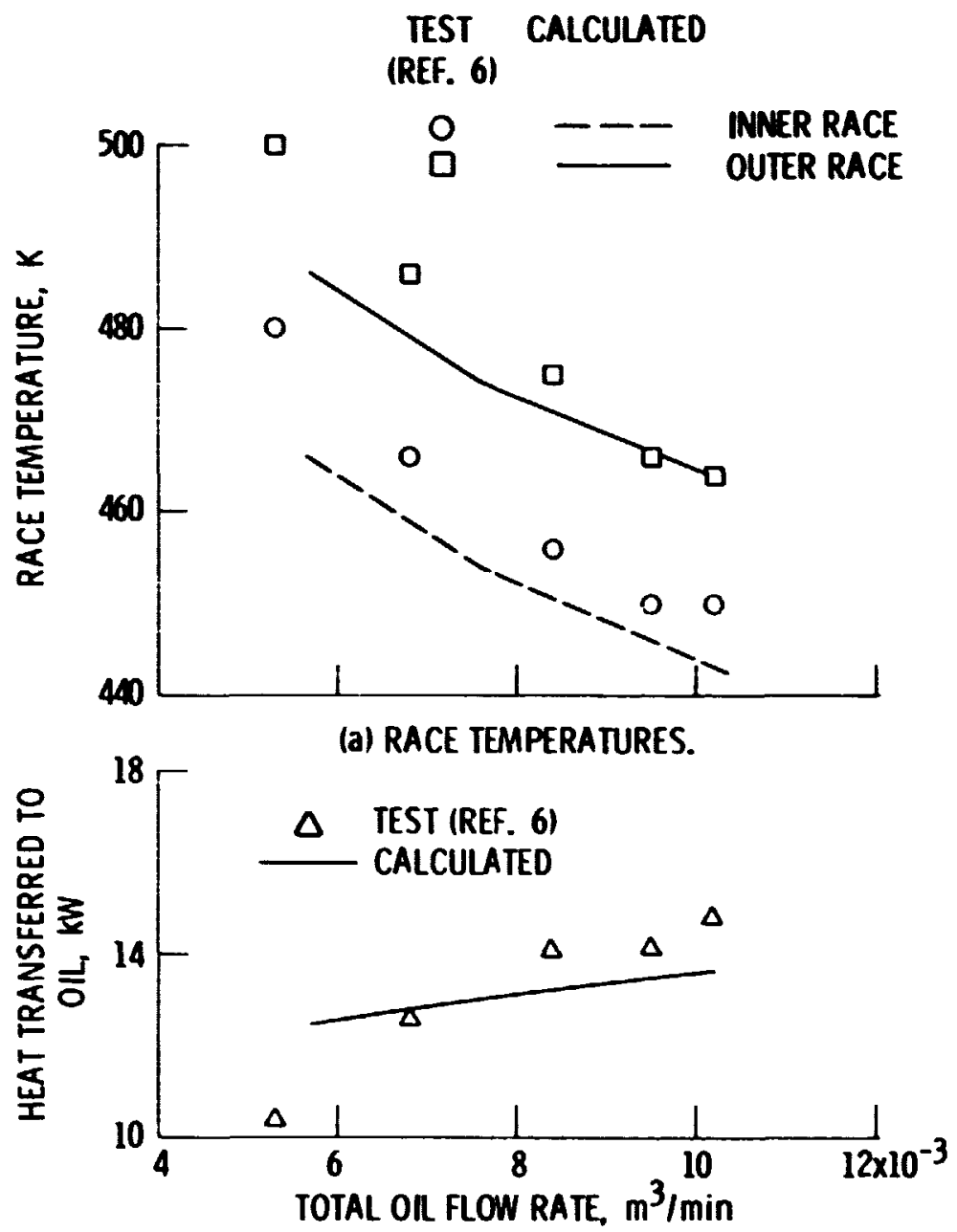

(b) HEAT TRANSFERRED TO LUBRICATING OIL

Figure 8. - Comparison of calculated and experimental bearing data using a diametral clearance of $-0.02 \mathrm{~mm}$ in the computer program. Shaft speed, $25500 \mathrm{rpm}$; radial load, $8900 \mathrm{~N}(2000 \mathrm{lb}) ;$ lubricant volume, 2 percent. 


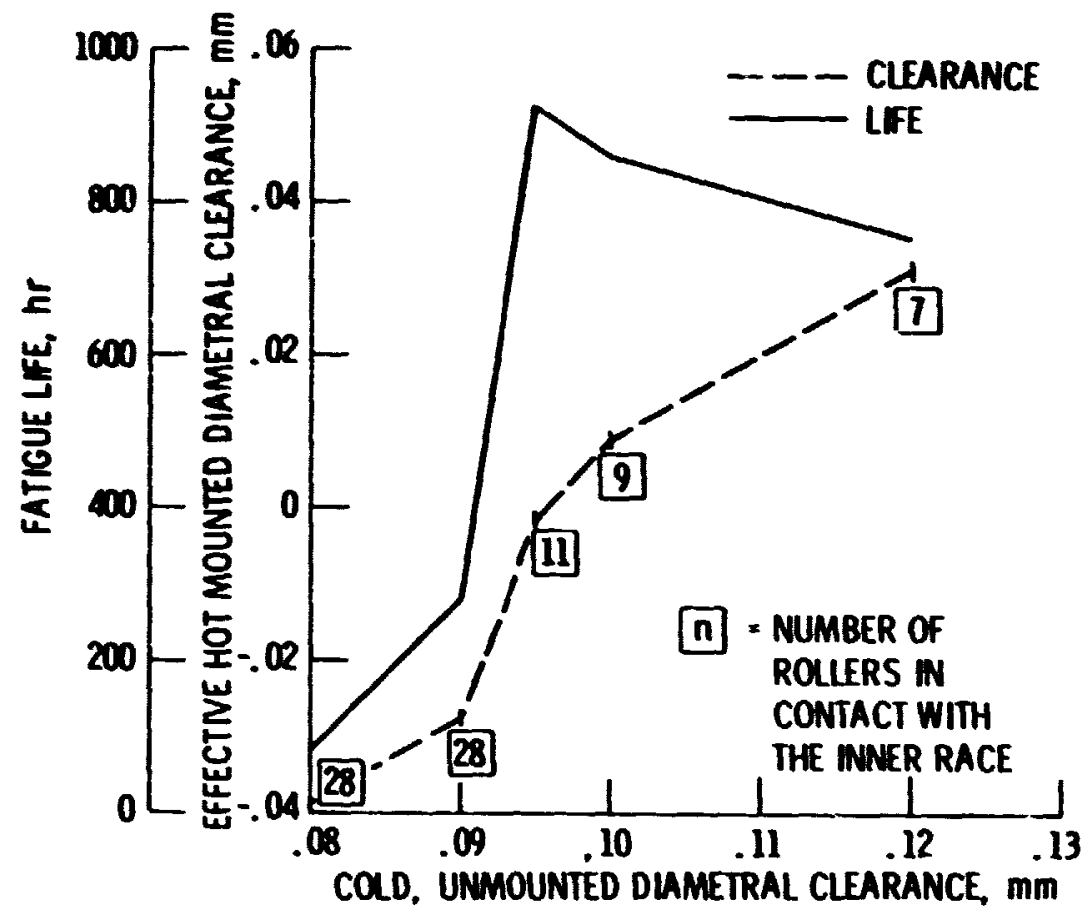

Figure 9. - Calculated values of effective hol mounted cleararce and fatigue life as functions of the cold, unmounted clearance. Shaft speed, $25500 \mathrm{rpm}$; radial load, $8900 \mathrm{~N}(2000 \mathrm{lb})$; oil flow rate, 0.0102 cubic $\pi$ ater per minute $(2.7 \mathrm{gal} / \mathrm{min})$; lubricant volume, 2 percent. 


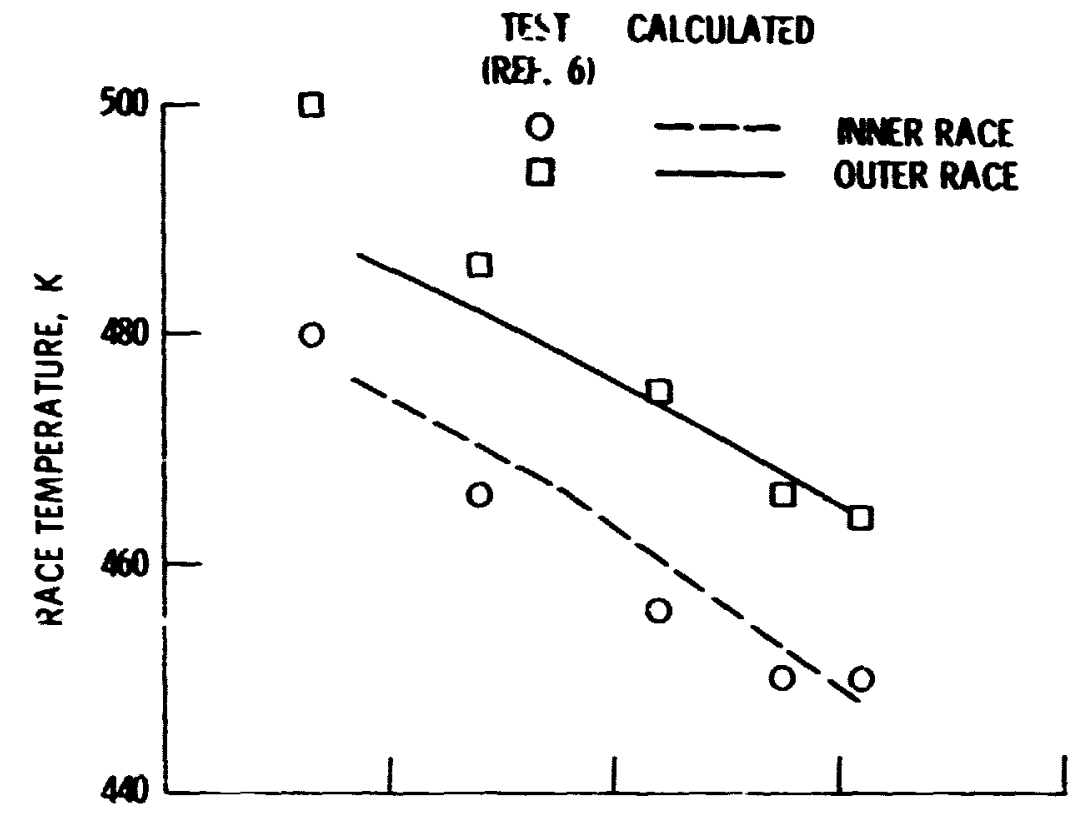

(a) RACE IEMPSRATURES.

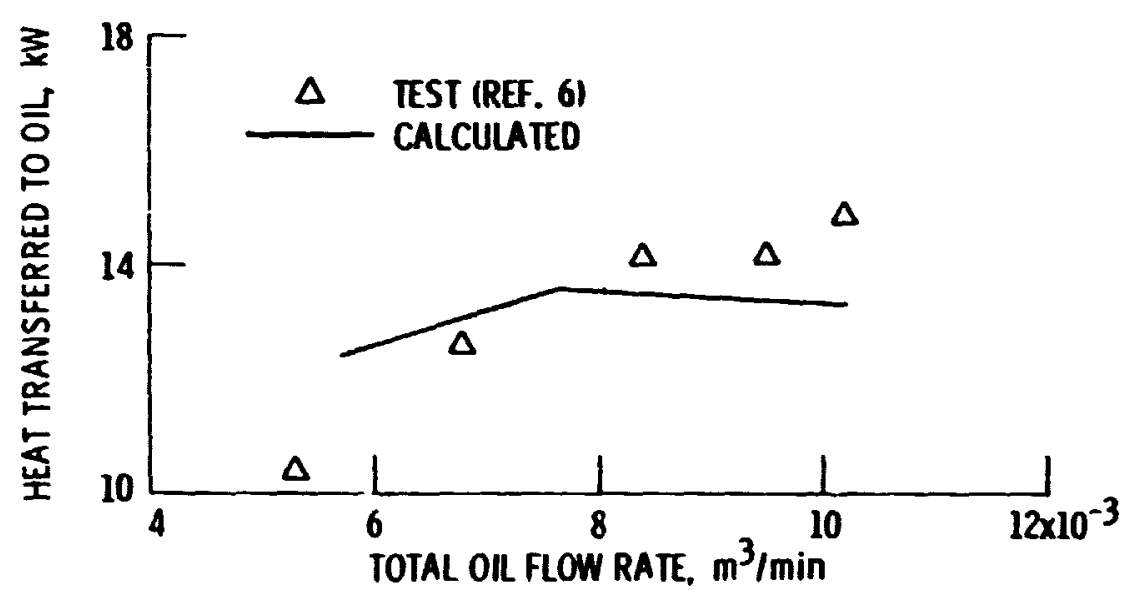

(b) HEAT TRANSFERRED TO LUBRICATING On.

Figure 10. - Comparison of calculated and test bearing data using an input cold diametral clearance of $0.09 \mathrm{~mm}$ in the computer program. Shaft speed, $25500 \mathrm{rpm}$; rasial load, $8900 \mathrm{~N}(2000 \mathrm{lb})$; lubricant volume, 2 percent. 


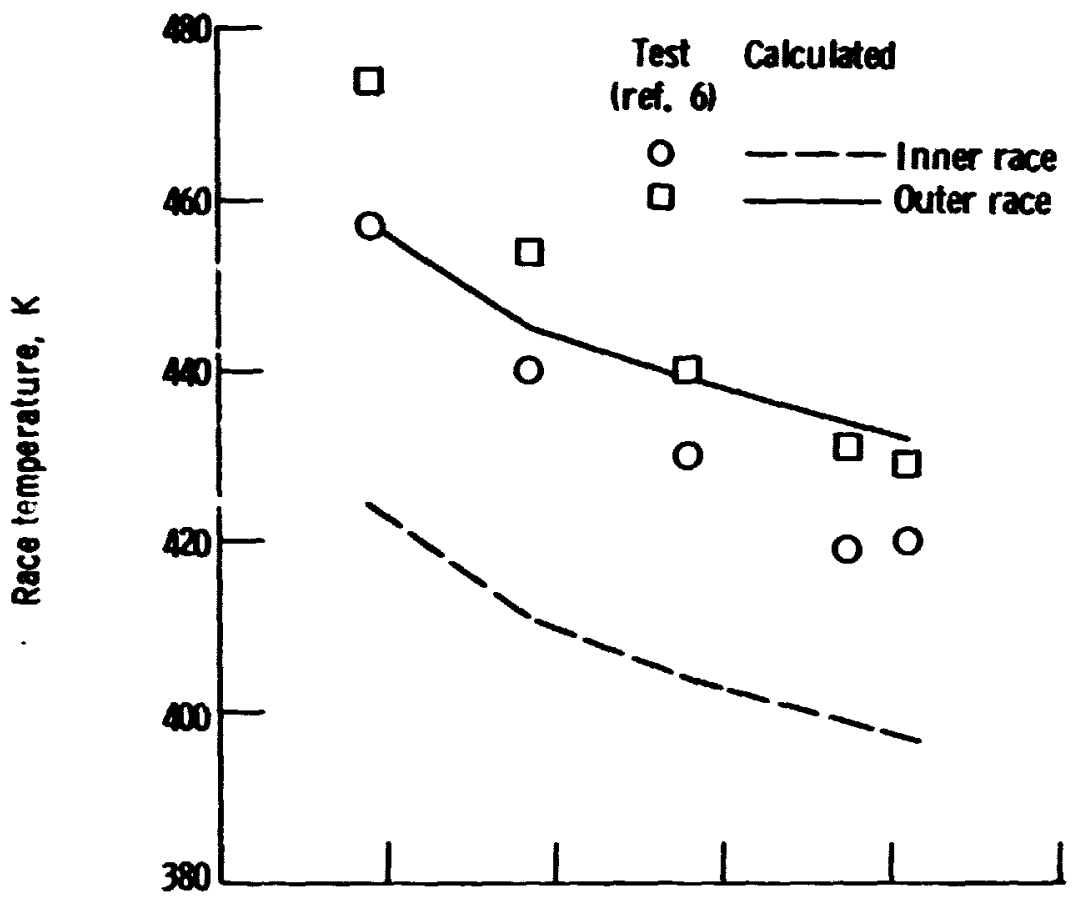

(a) Race temperatures.

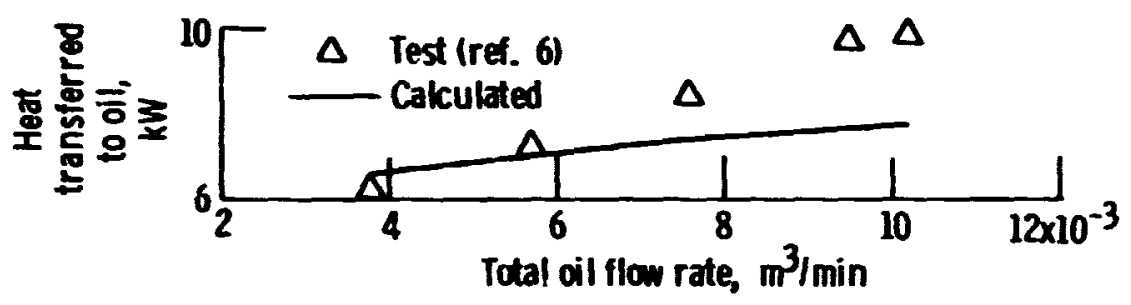

(b) Heat transterred to lubricating oil.

Figure 11. - Comparison of cakulated and experimental bearing data using a cold diametral clearance of $0.09 \mathrm{~mm}$ in the computer program. Shaft speed, $20000 \mathrm{rpm}$; radial load, $8900 \mathrm{~N}(2000 \mathrm{lb})$; lubricant volume, 2 percent. 


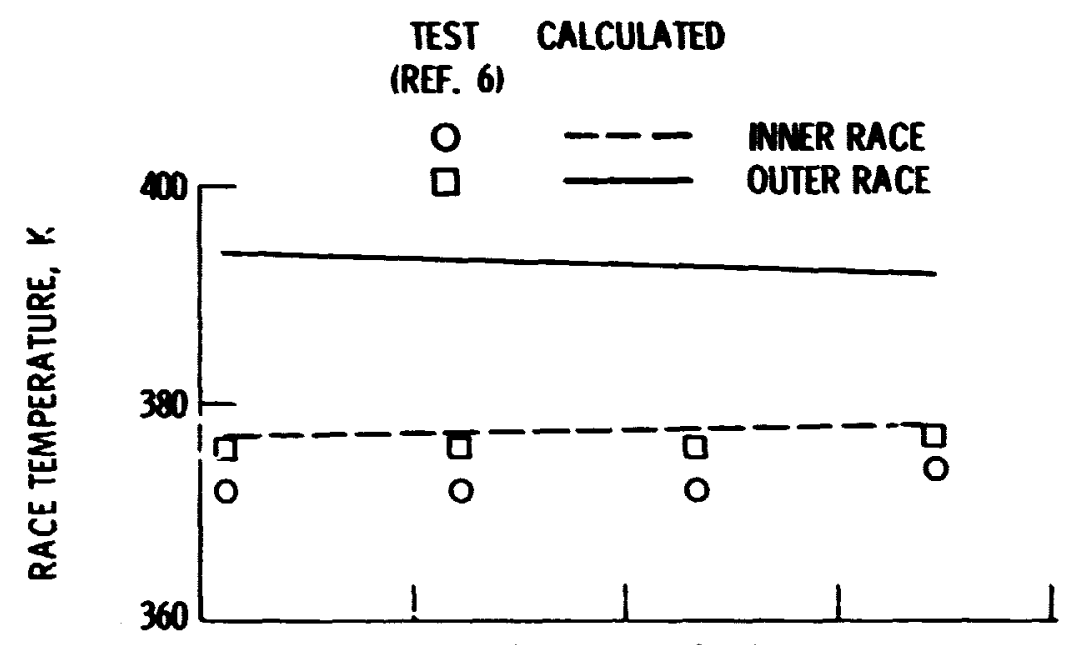

(a) RACE TEMPERATURES.

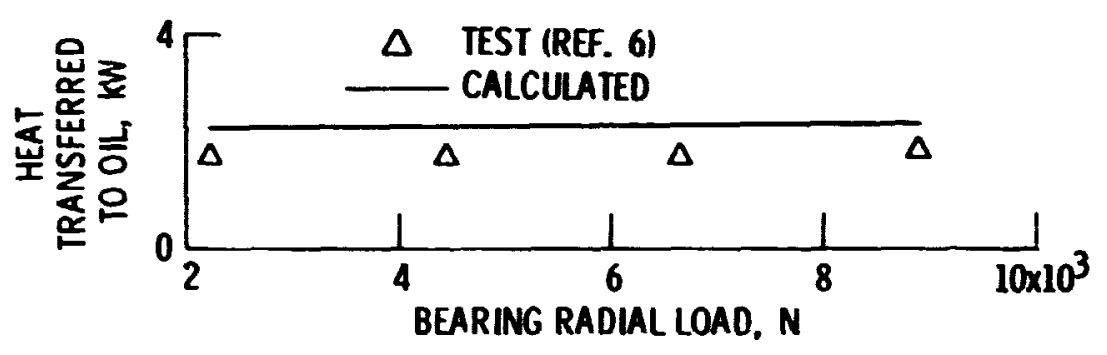

(b) HEAT TRANSFERREO TU LUBRICATING OIL.

Figure 12. - Comparison of test data with values calculated using a cold diametral clearance of $0.12 \mathrm{~mm}$ in the computer program. Shaft speed, $10000 \mathrm{rpm}$; total oil flow rate, 0.0102 cubic meter per minute $(2.7 \mathrm{gal} / \mathrm{min})$; !ubricant volume, 2 percent. 


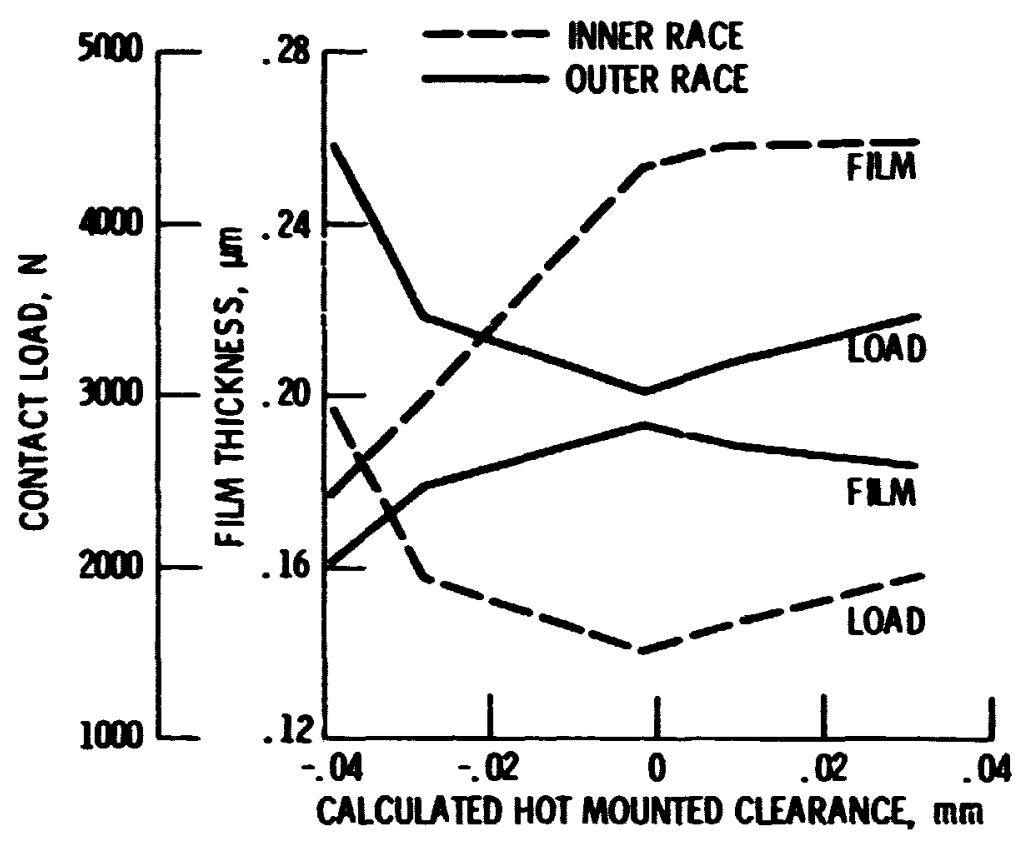

Figure 13. - Film thickness and contact load at the most heavily-loaded roller as a function of calculated hot, mounted clearance. Shaft speed, $8500 \mathrm{rpm}$; lubricant volume, 2 percent; oil flow rate, 0.0102 cubic meter per minute $(27$ gal/min), load, $8900 \mathrm{~N}$.

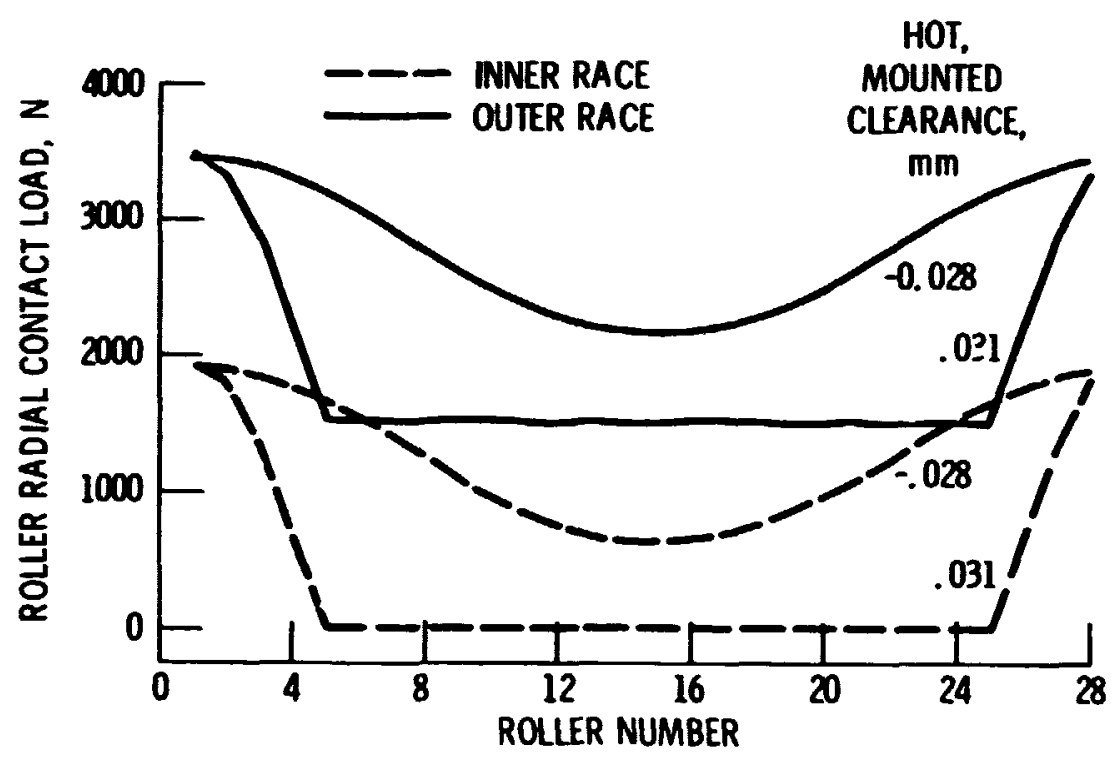

Figure 14 - Roller-race contact load variation with roller pesition for two values of clearance. Applied load at number 1 roller position. Shaft speed, $25500 \mathrm{rpm}$; radial load, $8900 \mathrm{~N}$; flow rate, 0.0102 cubic meter per minute $(2.7 \mathrm{gg} / \mathrm{min})$; lubricant volume, 2 percent. 


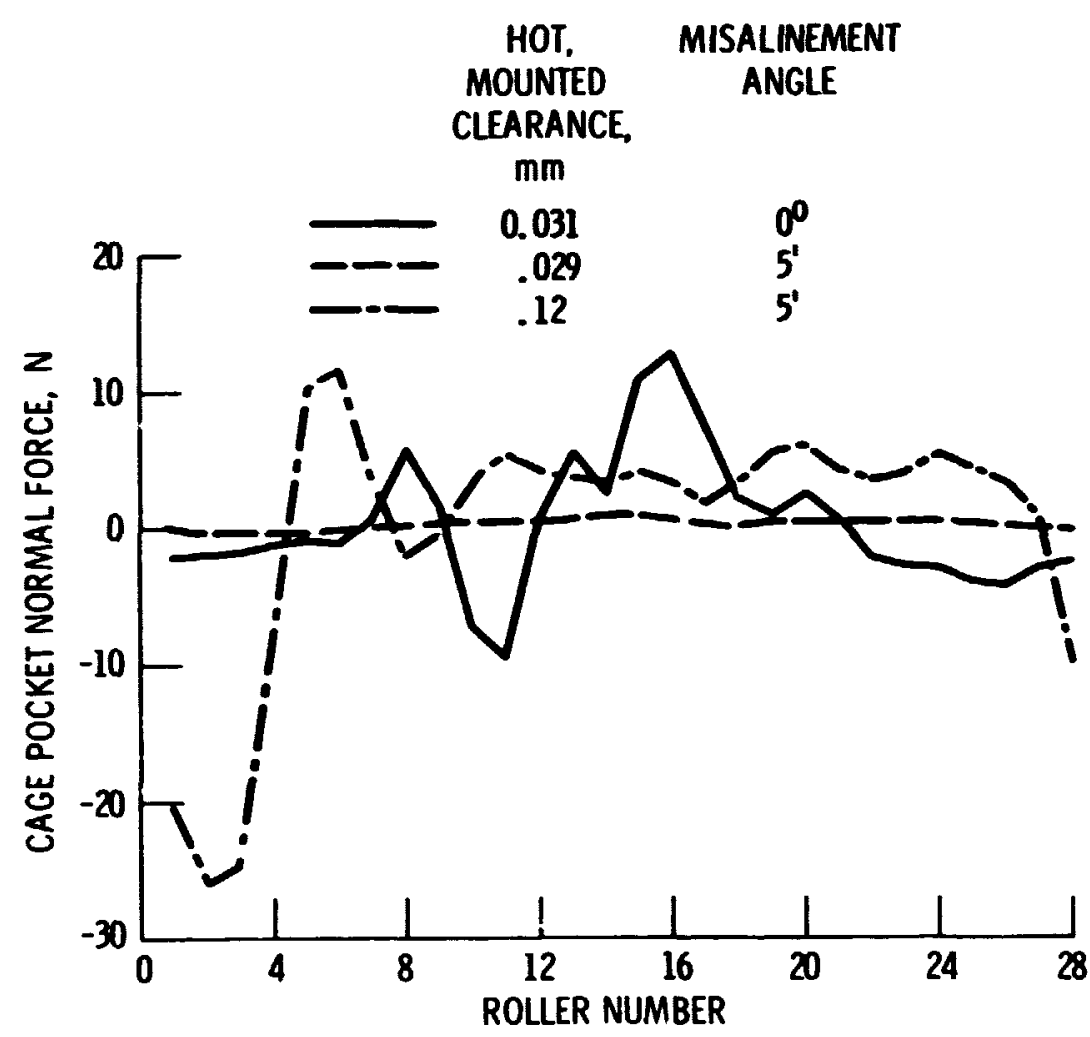

Figure 15. - Cage pocket forces as a function of roller number. Positive force is the cage pushing the roller. Bearing load at roller number l. Shaft speed, $25500 \mathrm{rpm}$; load, $8900 \mathrm{~N}$; flow rate, 0.0102 cubic meter per minute $(2.7 \mathrm{gal} / \mathrm{min})$; lubricant volume, 2 perceni. 


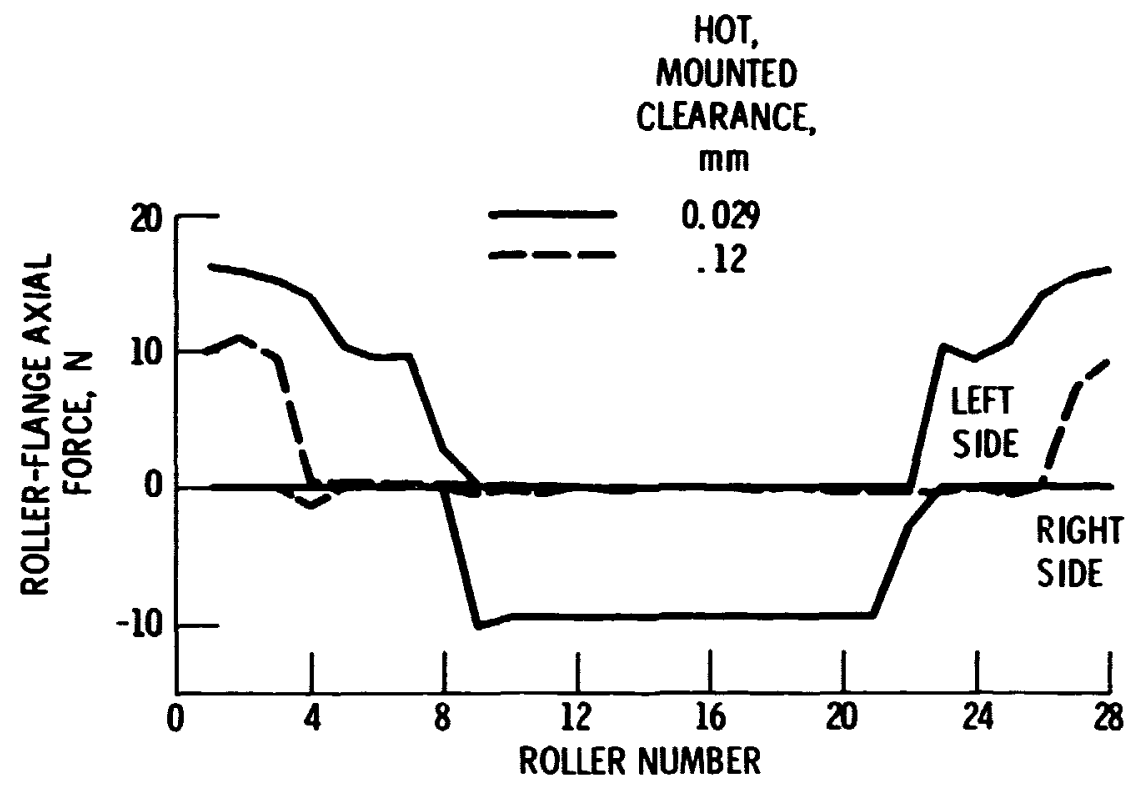

Figure 16. - Roller-flange forces as a function of roller number. Misalinement angle, 5 minutes. Shaft speed, $25500 \mathrm{rpm}$; load, $8900 \mathrm{~N}$; lubricant flow rate, 0.0102 cubic meter per minute ( $2.7 \mathrm{gal} / \mathrm{min}$ ); lubricant volume, 2 percent; bearing load at roller number 1 position.
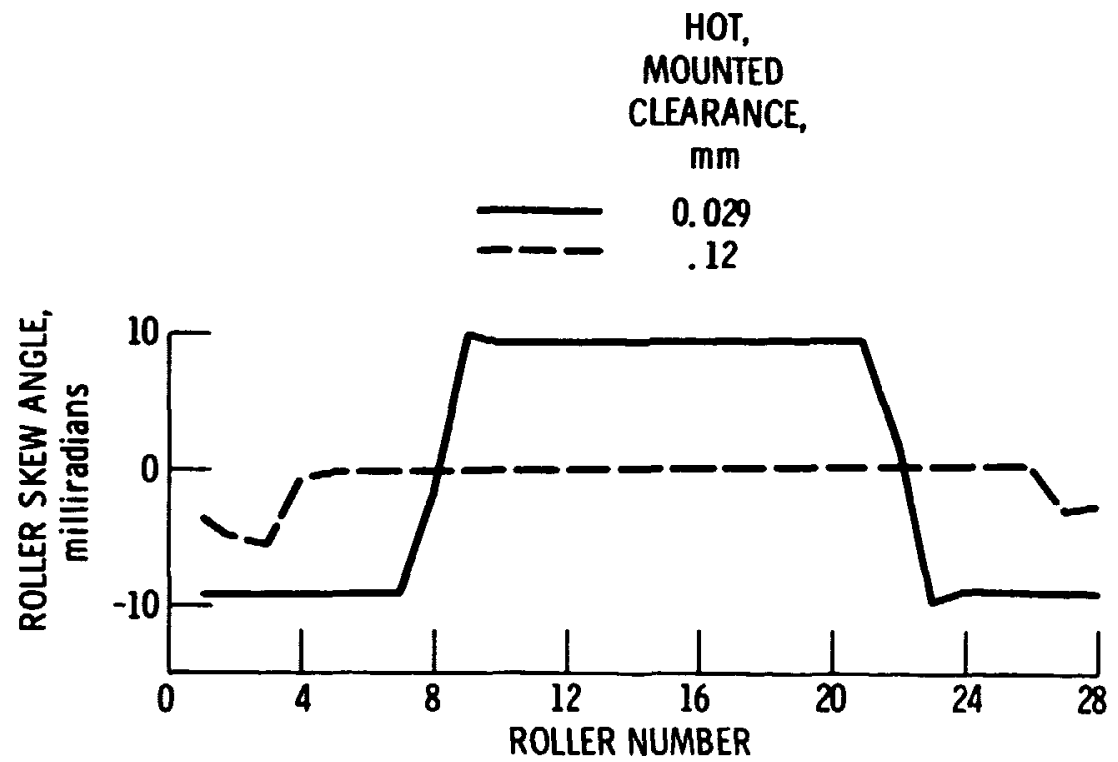

Figure 17. - Roller relative skew angle as a function of roller position. Bearing load of $8900 \mathrm{~N}$ at roller number 1 position. Misalinement angle, 5 minutes. Shaft speed, $25500 \mathrm{rpm}$; lubricant flow rate, 0.0102 cubic meter per minute $12.7 \mathrm{gal} /$ min); lubricant volume, 2 percent. 